\title{
CAPÍTULO II ACCIÓN CULTURAL POPULAR Y LA EDUCACIÓN DEL CAMPESINADO COLOMBIANO
}

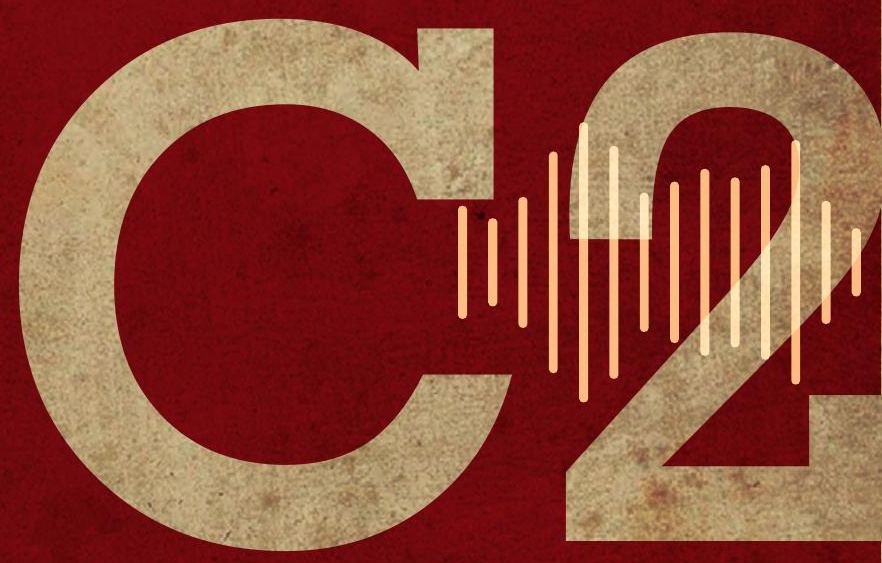



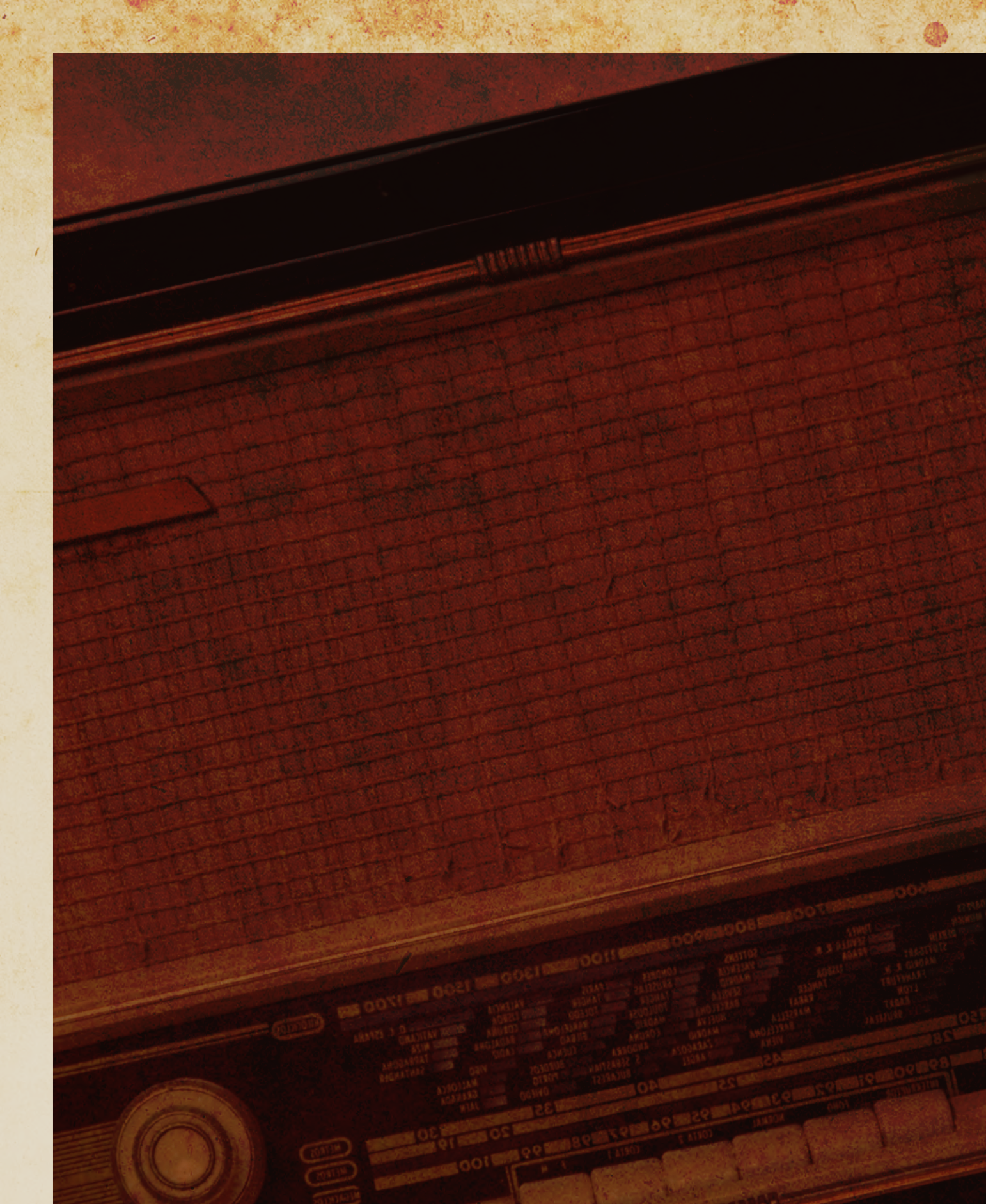


\section{ACCIÓN CULTURAL POPULAR Y LA EDUCACIÓN DEL CAMPESINADO COLOMBIANO}

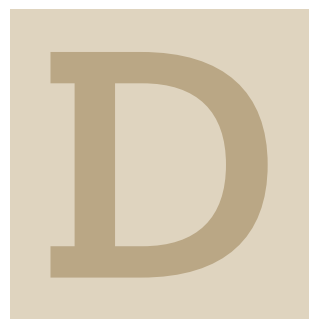

esde su creación en 1947, Radio Sutatenza y la organización Acción Cultural Popular, ACPO, tuvieron un rápido crecimiento tanto en infraestructura como en el cubrimiento de su acción, pues alcanzó a impactar en la mayor parte del país.

Para cumplir con los objetivos propuestos y ante la constante acogida de la obra de Salcedo, Acción Cultural Popular se vio en la constante obligación de ir ajustando su estructura organizativa. A medida que la institución fue creciendo, nuevos retos se presentaron. Diferentes gobiernos como el de Rojas Pinilla, el de Guillermo León Valencia y el de Alberto Lleras Camargo vieron en esta obra la posibilidad de cumplir con el papel educativo del Estado en aquellas regiones apartadas; por eso, mediante la adjudicación de contratos, inyectaron recursos a ACPO. Por ejemplo, se suscribieron contratos para cualificar a maestros rurales mediante clases dadas a través de la radio.

Acción Cultural Popular tuvo un constante apoyo por parte de la Iglesia, lo que permitió que la obra se extendiera a lo largo y ancho de la mayoría del territorio nacional. Es así como una buena cantidad de párrocos, especialmente de la región centro del país, hicieron parte del desarrollo de las escuelas radiales en sus centros de influencia.

Este capítulo analiza la consolidación de Acción Cultural Popular como una institución, cuál fue el camino que se fue trazando a partir de sus principios, los objetivos propuestos y la organización de una estructura administrativa. Además, 
analiza el modelo educativo utilizado en las Escuelas Radiofónicas, denominado Educación Fundamental Integral y los diferentes medios de acción utilizados para lograr el objetivo: educación para el campesinado colombiano.

ACPO, con la educación del campesinado por medio de la radio, logró generar un proceso de formación de líderes, que hicieron parte posteriormente de organizaciones rurales como las juntas veredales. En este último sentido, ACPO fue un promotor de una reforma agraria que le permitiera al campesino colombiano obtener tierras para su cultivo y explotación que lo llevaran a tener condiciones de vida más dignas.

Las fuentes primarias trabajadas en este capítulo son, principalmente, el semanario El Campesino, periódico creado por Acción Cultural Popular en el año de 1958, y los informes entregados por ACPO a la Conferencia Episcopal, desde el año de 1955 hasta 1964 y el de 1967. Igualmente, se hará uso de otras fuentes primarias como las cartillas de apoyo trabajadas por ACPO en sus Escuelas Radiofónicas. Cartillas que contenían información y ejercicios correspondientes a las nociones básicas de aprendizaje establecidas para la formación del campesinado.

Acción Cultural Popular creó una editorial, que le permitió editar una amplia gama de textos como eran las cartillas mencionadas, pero también imprimió los resultados de estudios realizados referentes al trabajo de Radio Sutatenza, las Escuelas Radiofónicas o, en general, de Acción Cultural Popular, como una organización que trabajó con diversos medios de comunicación para cumplir con el objetivo de educar al pueblo campesino.

\section{La estructura organizativa de ACPO}

Acción Cultural Popular fue reconocida como una institución con la aprobación de la personería jurídica 260 del Ministerio de Justicia. Esa decisión se dio el 18 de octubre de 1949, un año después de que Radio Sutatenza iniciara labores en el municipio de Sutatenza en el departamento de Boyacá. Aunque en los primeros años solo estaba la pequeña emisora funcionando, posteriormente hicieron parte de la institución otros proyectos como el periódico El Campesino, que se publicaba semanalmente y estaba dirigido especialmente a la población campesina; la Editorial Andes, que se utilizaba para imprimir todas las cartillas y libros que se utilizaban para acompañar las clases radiales; las bibliotecas campesinas que se implementaron para incentivar el hábito de la lectura y también para fortalecer los temas tratados en las clases; y entre otros, la prensadora de discos, que se utilizaba 
para realizar grabaciones musicales, también apoyaba el proceso de formación así como la grabación de las clases para ser transmitidas por las emisoras.

Desde los primeros años de funcionamiento de Radio Sutatenza y Acción Cultural Popular, la institución tuvo el reconocimiento de personas como el presidente Mariano Ospina Pérez y el Papa Pío XII, quien en 1953 impartió un mensaje y la bendición al campesinado colombiano. En abril 11 de ese mismo año, el cardenal Crisanto Luque ratifica la Fundación de ACPO en compañía del obispo de Tunja, Ángel María Ocampo, de los sacerdotes José Joaquín Salcedo y José Ramón Sabogal, y de un representante de los campesinos. ACPO recibió también el apoyo de la Unesco. Durante cuatro años, hasta 1957, se trabajó en la preparación y validación de las cartillas de lectura y en el diseño de las láminas de lectura, escritura y aritmética utilizadas por los profesores radiales como ayuda complementaria.

A partir de la aprobación de la personería jurídica de ACPO, se constituyó una organización administrativa, que fue conformada inicialmente por medio del trabajo realizado por las Escuelas Radiofónicas. Los primeros indicios que se encuentran de esta organización están plasmados en el texto de Francisco Javier Mejías, S. J. Las Escuelas Radiofónicas, donde se visibiliza la labor realizada por el maestro principal que era el padre Salcedo y por el maestro auxiliar, que era un campesino, pero con nociones de lectura y escritura necesarias para apoyar al resto de estudiantes campesinos. Mejía definiría a este maestro auxiliar como el “último sillar en que descansa la estructura espiritual de las escuelas"95.

A través de los informes que periódicamente debía entregar Acción Cultural Popular a la Conferencia Episcopal, se evidenció la organización administrativa que se estableció para el funcionamiento de la institución. Por ejemplo, en el informe de 1955 a los maestros auxiliares se les denominó Auxiliares Inmediatos, y ya hacían parte de una organización parroquial.

En parroquias donde las Escuelas están organizadas siguiendo las normas indicadas por la institución, los Auxiliares inmediatos se reúnen con su párroco y el Representante Parroquial y forman una milicia de cooperadores abnegados en el apostolado. Ellos reciben las consignas del Párroco y las cumplen; son los apóstoles en su medio 96.

95. Revista Javeriana, No. 160, noviembre de 1949 p. 288

96. Informe al Eminentísimo señor Cardenal y a los Excelentísimos prelados de Colombia reunidos en Conferencia Episcopal en 1955. Acción Cultural Popular. Escuelas Radiofónicas. p.2 
La organización desarrollada correspondió al crecimiento que tuvo ACPO con sus Escuelas Radiofónicas. Al finalizar la década del 40 alcanzó un número de 90 escuelas y alrededor de 7.000 estudiantes ubicados en los municipios cercanos a Sutatenza ${ }^{97}$.

De acuerdo con las fuentes primarias halladas, en 1957 se encuentra el primer organigrama de la institución, cuando se presentó el informe de ACPO a la "Venerable Conferencia Episcopal", correspondiente a los años de 1957 y $1958^{98}$. El crecimiento de la institución permite ver una amplia y compleja organización que había trascendido más allá de las labores realizadas por los párrocos en las Escuelas Radiofónicas.

Según ese organigrama, la estructura organizativa de ACPO respondía a las orientaciones de la Conferencia Episcopal. La institución era dirigida por una junta directiva y por un director general que era el padre José Joaquín Salcedo. El resto de las funciones estaban agrupadas en tres secciones que inicialmente correspondían a la dirección de las Escuelas Radiofónicas, a la gerencia administrativa, y a la gerencia comercial, pero que posteriormente fueron sustituidas por una división comercial, una división cultural y una división administrativa.

En aproximadamente siete años, Acción Cultural Popular, pasó de operar con unas pocas personas en el municipio de Sutatenza, a tener un buen número de empleados que cubrieran los diferentes cargos creados para el funcionamiento de una institución. Ya no se usaba un medio para la educación, como fue la radio, sino que convergían varios medios como las cartillas o los afiches.

El crecimiento de Acción Cultural Popular no se detuvo. En el informe de 1957 se previó trabajar en otras áreas y con otros medios. Uno de ellos fue el semanario El Campesino, que fue el segundo medio en importancia utilizado por Acción Cultural Popular, pues tuvo circulación nacional y se identificaba a sí mismo como el medio del campesinado colombiano. Su primera edición tituló: “Un semanario al servicio y en defensa de los campesinos de Colombia"99.

La estructura administrativa y la organización de Acción Cultural Popular contó con el apoyo expreso de la Iglesia Católica, por ser esta una obra de carácter diocesano, y también contó con la colaboración de personalidades de la vida pública, tanto así que varias de ellas hicieron parte de la Junta Directiva.

97. Revista Javeriana, No. 160, noviembre de 1949 p. 288

98. Informe a la Venerable Conferencia Episcopal, 1957 - 1958, Bogotá. pp. 22

99. El Campesino, Bogotá, 29 de junio de 1958. 
Mediante los diferentes informes entregados a la Conferencia Episcopal, ACPO ratificó su obediencia a las disposiciones de la Conferencia. En el informe que cubre los años de 1961 a 1964 reafirmó que Acción Cultural Popular se encontraba "bajo la orientación de la Venerable Conferencia Episcopal y es gobernada por la Asamblea General, el Consejo de Gobierno, la Junta Directiva y el Director General". ${ }^{100}$

Bajo esta estructura era responsabilidad del Consejo de Gobierno tomar las más altas decisiones y efectuar los nombramientos principales. Entre tanto, la Junta Directiva estaba a cargo de las decisiones “ordinarias". Por esa razón, mientras la primera se reunía de una a tres veces por año, la segunda lo hacía semanalmente. Sin embargo, el peso de la planeación, dirección y control recayó y permaneció sobre la figura de José Joaquín Salcedo.

Paralelo a la definición de los principios que rigieron a ACPO, se fue diseñando la estructura de la institución. Esta se transformó en varias ocasiones, y los diferentes informes enviados a la Conferencia Episcopal dan testimonio de los cambios realizados. El realizado durante el periodo de 1959 a 1960 no fue el último; en la presentación del informe que cubrió tres años, entre 1961 y 1964, se presentó una nueva carta de organización de Acción Cultural Popular.

De esta manera, Acción Cultural Popular se consolidó como una organización de carácter nacional, cubriendo amplios sectores de los departamentos de Antioquia, Atlántico, Bolívar y Boyacá, entre otros, con un total de 238.583 estudiantes. Además, con una circulación anual de El Campesino de 3.388.542 ejemplares en todo el país. El crecimiento en el número de estudiantes y el número de escuelas llevó a crear un sistema que pudiera cumplir con los objetivos propuestos a través del tiempo, pero sobre todo, que pudiera llevar educación a los sectores menos favorecidos.

\section{Principios de ACPO}

Mientras se iba consolidando la organización administrativa de Acción Cultural Popular, se fue trabajando en los principios que regirían a la institución. Hernando Bernal Alarcón, ${ }^{101}$ colaborador y funcionario de ACPO, menciona que la publicación

100. Informe a la Venerable Conferencia Episcopal, 1961 a 1964, Bogotá. p. 7

101. Hernando Bernal Alarcón fue desde el año de 1964 director del departamento de Sociología y de Planeación y Programación de Acción Cultural. Él era un sociólogo de la Universidad Javeriana, con magíster en sociología para el desarrollo de la Universidad de Wisconsin. Bernal Alarcón escribió varias publicaciones relacionadas con Acción Cultural Popular y la Educación Fundamental Integral. Fue uno de los colaboradores más cercanos a monseñor Salcedo. 
de estos principios ${ }^{102}$ se realizó el 5 de septiembre de 1956. Sin embargo, en las fuentes revisadas se encuentran en el informe correspondiente a los años de 1957 y 1958. A lo largo de ocho puntos se demarcaba el camino a seguir por ACPO, sus principios y sus fines. Este primer documento oficial decía así:

\section{PRINCIPIOS IDEOLÓGICOS DE ACCIÓN CULTURAL POPULAR103}

1. ACCIÓN CULTURAL POPULAR es una obra de la Iglesia que tiene como fin ayudar a la dignificación del pueblo y especialmente del campesino adulto, por medio de una educación integral que abarque la cultura básica y la preparación para la vida social y económica con el fundamento de una auténtica formación religiosa.

2. ACCIÓN CULTURAL POPULAR considera que es un deber para toda la sociedad, y de un modo especial para la Iglesia, el colaborar decididamente en el desarrollo de los valores espirituales, culturales, sociales, familiares y aún de perfección individual, que Dios ha puesto en cada uno de los hombres como semilla que habría de fructificar según la naturaleza y el plan del Creador. Por eso facilita al hombre del pueblo los medios que han de ayudarle al cumplimiento de su deber de perfección individual, familiar y social.

3. Para cumplir eficazmente la finalidad que persigue, ACCIÓN CULTURAL POPULAR debe promover una conciencia pública de gran sensibilidad social sobre los problemas del campo, con base en un concepto cristiano de la agricultura y de la vida campesina, frente al concepto puramente técnico y económico.

4. ACCIÓN CULTURAL POPULAR, como institución, es una idea dinámica organizada, con un auténtico sentido jerárquico, que aspira a la integración de sus colaboradores a la obra de la Iglesia, aunando los esfuerzos de todos en una voluntad de apostolado, pero con profundo respeto a su personalidad e iniciativas

5. Las actividades de ACCIÓN CULTURAL POPULAR favorecen la creación de un movimiento desarrollado por unos militantes que encarnen una doctrina de vida en una acción solidaria organizada.

102 BERNAL, Hernando. Acción Cultural Popular, de la realidad a la utopía, Bogotá, Fundación Cultural Javeriana, 2005, p. 118

103 Informe a la Venerable Conferencia Episcopal, 1957 - 1958, Bogotá, p. 3 
6. ACCIÓN CULTURAL POPULAR centra sus actividades en la comunidad parroquial. Al facilitar su colaboración a las parroquias, tiene el criterio de ayudar al mayor número, aunque solo sea con el mínimo de medios y elementos, para despertar en ellos inquietudes e iniciativas.

7. ACCIÓN CULTURAL POPULAR, como parte de la acción de la comunidad parroquial, con espíritu de colaboración y coordinación, crea un ambiente y facilita unos medios que contribuyan al desarrollo de otras obras parroquiales.

8. El párroco, como director del movimiento de Escuelas Radiofónicas en la comunidad parroquial, ocupa en Acción Cultural Popular un puesto activo de orientación y dirección como miembro de la Asamblea General.

Los principios, de una parte, reafirmaron la voluntad de Acción Cultural Popular para ayudarle y colaborarle al campesinado por medio de la educación. Los beneficiarios de esta obra lograban adquirir una preparación que les permitía enfrentarse a la vida social y económica, tal y como Salcedo lo venía promulgando desde el inicio del proyecto. Sin embargo, los principios ponen de manifiesto la necesidad de trascender en esa formación más allá de la vida pública del campesino, más allá de la vida en sociedad, entrando a espacios como el de la familia y a ámbitos de carácter individual. La formación de ACPO trascendía en general a todos los espacios, tanto los públicos como los privados, todos ellos influidos por los valores espirituales inherentes a la Iglesia Católica.

Esta preocupación se manifestó en los informes de la Conferencia Episcopal de 1956 y 1957, cuando Salcedo afirmaba frente a la formación de los Auxiliares Inmediatos que:

Estimamos que es necesaria una acción complementaria que haga más vivo el sentido cristiano del amor, la consideración por la esposa y por los hijos, que ilustre a los padres sobre sus deberes para con la familia en puntos como la educación y la economía del hogar. Nos inquieta profundamente que estos Auxiliares Inmediatos, que ya han cumplido su proceso de formación tanto intelectual como moral, no reciban las sugestiones para irradiar un apostolado católico ${ }^{104}$.

104. Informe al Eminentísimo señor Cardenal y a los Excelentísimos prelados de Colombia reunidos en Conferencia Episcopal en 1955. Acción Cultural Popular. Escuelas Radiofónicas, p.2 
Acción Cultural Popular buscaba que sus principios abarcaran no solo la mayoría sino la totalidad de las acciones del campesinado, pero además que el grupo de personas a las que se les llegaba por medio de las Escuelas Radiofónicas tuvieran la posibilidad de ser, por un lado, multiplicadores de los beneficios recibidos, pero por otro, que como lo indicaban los principios, se convirtieran en verdaderos militantes de un grupo que pudiera organizarse y buscar conjuntamente el desarrollo de sus propias comunidades. Salcedo de esta manera proyectaba a ACPO como una institución capaz de generar identidades colectivas, identidades de grupo para influir activamente en las decisiones que tenían que ver con la calidad de vida del campesinado.

Los principios ideológicos de Acción Cultural Popular, en general, plasmaron el accionar de la Institución, la relación con la Iglesia, la relación con el campesinado, el papel que debían cumplir los párrocos y los estudiantes de las Escuelas Radiofónicas, pero, sobre todo, el carácter católico de la obra y la necesaria obediencia a una organización jerárquica.

La etapa denominada como "el origen" empezó a cerrarse con la publicación de los principios ideológicos. A partir de este momento, Acción Cultural Popular se convirtió en un proyecto maduro y se inició lo que aquí denominamos como la etapa de consolidación. En general, la obra ya contaba con una organización administrativa, con unos principios que la regían y con unos objetivos propuestos.

\section{La Educación Fundamental Integral}

El objetivo principal de ACPO desde su nacimiento fue la capacitación y formación del campesinado colombiano que había carecido de las posibilidades de acceder a la educación formal. Para lograrlo, decidió el padre José Joaquín Salcedo utilizar los medios de comunicación y especialmente la radio. De allí se originó una propuesta de educación para adultos denominada Educación Fundamental Integral que contó, a partir de la experiencia, con un sustento teórico, unas metodologías y unos medios para sus logros. Esta sección del capítulo hace un análisis de los aspectos más importantes de la Educación Fundamental Integral, considerada una propuesta novedosa para la primera mitad del siglo XX por la conformación de las Escuelas Radiofónicas y el apoyo multimedial que tuvieron las diferentes clases radiales. Las fuentes utilizadas principalmente son el periódico El Campesino, medio de Acción Cultural Popular creado en 1958; las cartas de los oyentes de las Escuelas 
Radiofónicas y los informes que ACPO presentó a la Conferencia Episcopal, como lo establecían los estatutos de la organización.

El análisis de la Educación Fundamental Integral, desde las fuentes sugeridas, muestra por una parte una perspectiva institucional, puesto que los informes que se presentan a la Conferencia Episcopal son redactados por la dirigencia de ACPO; de otra parte, la imagen que se proyecta de la institución y de su modelo a través del periódico, como un instrumento de divulgación de los principios y valores de ACPO, pero también como un escenario de diálogo entre los diferentes actores sociales que confluyen en el proyecto de la Educación Fundamental Integral. La relación entre el campesinado y la institución desde la mirada de los propios estudiantes de las Escuelas Radiofónicas se presenta con mayor claridad en las cartas. Allí comentan sobre sus problemas, sus necesidades y sus logros y reconocen sus contextos más cercanos en relación con la Educación Fundamental Integral y las Escuelas Radiofónicas.

Los últimos años de la década del cincuenta son importantes dentro del proyecto de ACPO, pues empieza a emerger el concepto de Educación Fundamental Integral, que se convirtió en el modelo utilizado en las Escuelas Radiofónicas. Se transitó por un camino que había llevado al campesinado exclusivamente, o principalmente, al aprendizaje de la lectura y la escritura, a una educación que afectaba prácticas, mentalidades, hábitos y formas de ser. ACPO incidía por esta vía en los diferentes ámbitos de la vida cultural, afectaba de esta manera "sobre los esquemas de pensamiento y de comportamiento; sobre las formas de realizar papeles sociales; sobre las instituciones; en una palabra, sobre el "way of life", la manera de vivir y de pensar". ${ }^{105}$ Desde esta perspectiva se consignó el concepto de Educación Fundamental Integral en el documento de los Principios y Medios de Acción de ACPO, concepto que parte de la UNESCO en 1955 y que lo define como:

El mínimo de conocimientos generales que tienen por objeto ayudar a los niños y adultos que no disfrutan de las ventajas de la instrucción escolar, a comprender los problemas peculiares del medio en que viven, a formarse una idea exacta de sus derechos y deberes tanto cívicos como individuales, y a participar más eficazmente en el progreso social y económico de la comunidad a que pertenecen. ${ }^{106}$

105. HOUTART, Francisco y PÉREZ, Gustavo. Acción Cultural Popular. Sus principios y medios de acción, consideraciones teológicas y sociológicas. Bogotá. ACPO, 1960. p. 37.

106. Etudes et Documents d'education, No. 15. 1955, p. 12 en CASTRO, Jorge. Acpo y el ideal de una progresión cultural: Génesis de las escuelas radiofónicas. Tunja. Revista Pensamiento y Acción. 2002. p. 56. 
Francisco Houtart y Gustavo Pérez, quienes ya habían trabajado juntos, fueron los dos sacerdotes encargados por ACPO para establecer los principios y los medios de acción necesarios para llevar a cabo el proceso de educación campesino mediante las Escuelas Radiofónicas ${ }^{107}$. El padre Francisco Houtart era sociólogo, director del Centro de Investigaciones Socio-Religiosas de Bélgica, profesor de la Universidad de Lovaina y Secretario General de la Conferencia Internacional de Sociología Religiosa; y el padre Gustavo Pérez también era sociólogo y director del Centro de Investigaciones Sociales de Colombia.

Para Houtart, la Iglesia Católica se encontraba en una crisis frente a los nuevos desafíos que planteaba la creciente urbanización en Europa, pero también en América Latina. En este sentido, las causas de las crisis eran, de una parte, externas, pues la misma urbanización proponía una "nueva sociedad, un nuevo tipo de grupo, nuevas instituciones, nuevas mentalidades, nuevas culturas". ${ }^{108}$

Houtart consideraba que había nuevas maneras de vivir y nuevas maneras de entender las diferentes mentalidades, lo que significaba que existieran también nuevos hombres. De tal manera que la nueva vida social se caracterizaba por poseer una especialización de funciones sociales como eran la vivienda, la escuela o el trabajo. Ya no existía un solo espacio donde el hombre encontrara reunida en su totalidad todas las especializaciones de la vida. Esas especializaciones, para Houtart, se presentaban en instituciones que podían ser escolares, de salud, de vivienda o sindicatos. Instituciones que generaban nuevas interacciones y relaciones sociales que daban origen a ese nuevo mundo social del hombre.

Desde la perspectiva de Houtart, la Iglesia no podía ya ser la única institución que respondiera a todos los problemas de la vida humana, puesto que las relaciones interhumanas no dependían exclusivamente del sitio de residencia de la mayoría de las personas, sino del grado de relaciones funcionales que se establecían. Las relaciones se establecen a partir de las especializaciones, es decir, de los intereses que tenga un grupo de personas. A partir de lo anterior, Houtart afirmaba que los procesos de urbanización y las especializaciones

107. En entrevista realizada por Gabriel Gómez a Hernando Bernal Alarcón, este último comenta que Francisco Houtart fue encargado por monseñor Salcedo para hacer una descripción sistemática de Acción Cultural Popular y de lo que se pensaba que era la institución. Houtart llamó a Gustavo Pérez y Camilo Torres, quienes habían sido estudiantes suyos en Lovaina, para que le colaboraran en dicho trabajo, que posteriormente se vio reflejado en el texto conocido por los miembros de ACPO como el Libro Azul.

108. HOUTART, Abbe. La mentalidad religiosa y su evolución en las ciudades. Bogotá, Universidad Nacional de Colombia, 1959, p. 10. 
hacían que la sociedad fuera más influyente que el individuo. Por último, Houtart planteaba que la creciente urbanización de los territorios llevaba a una mayor movilidad geográfica, un problema, puesto que la Iglesia Católica fue "concebida y organizada hasta ahora como para un sitio geográfico fijo, hasta tal punto que la movilidad de las gentes ha sido considerada como un mal, como un mal social y también como un mal religioso". ${ }^{109}$

Estas eran las causas externas de la crisis religiosa, pero también existieron, según Houtart, unas causas internas de la misma Iglesia que tenían que ver con una institución que mantenía antiguas estructuras que no respondían a los nuevos ambientes y a las nuevas instituciones sociales. Se necesitaba una acción religiosa organizada desde el punto de vista funcional que se acomodara a las nuevas sociedades.

Houtart entendía que para ese momento (1959), se estaba dando un cambio social que exigía una nueva síntesis de la vida religiosa, donde los cambios de las personas modificaban la vida espiritual, y donde se debía continuar con la búsqueda de nuevos medios y de una nueva mentalidad religiosa. ${ }^{110}$

La elección de los dos autores del texto Acción Cultural Popular. Sus principios y medios de acción, consideraciones teológicas y sociológicas, da cuenta del interés de ACPO por lograr un documento ideológicamente consistente y que respondiera al pensamiento contemporáneo. Era un momento en que hacían presencia particularmente las corrientes teológicas y sociológicas distintivas de la Universidad de Lovaina. Tanto Houtart como varios miembros del clero colombiano tenían vinculación con la Universidad de Lovaina, el primero como profesor y los segundos como estudiantes a partir de la colaboración del cardenal Crisanto Luque, quien había apoyado desde los inicios el proyecto de Radio Sutatenza y quien estaba "interesado en mejorar la calidad de su clero" . ${ }^{111}$

Desde la corriente ideológica planteada a través del Libro Azul, ${ }^{112}$ de Houtart y Pérez, para que ACPO actuara en la vida cultural del campesino requería influir en los valores, pues ellos eran la base de la actividad y de la actitud de los hombres; proporcionar mediante una acción pedagógica unos conocimientos y unas

109. HOUTART, Abbe. La mentalidad religiosa y su evolución, op, cit. p. 15.

110. Ibid., p. 20.

111. ARIAS, Ricardo. El Episcopado Colombiano: Intransigencia y Laicidad (1850 - 2000), Bogotá, Ediciones Uniandes, 2003, p.196.

112. Así se conocía institucionalmente el libro escrito por HOUTART, Francisco y PÉREZ, Gustavo. Se le llamó el Libro Azul por el color de su portada. 
técnicas; y generar los ambientes necesarios para que el campesino exigiera una organización más justa y estuviera preparado frente a un cambio cultural.

A partir de lo anterior se apreciaba la relación existente entre la Educación Fundamental Integral y el desarrollo. Esta educación suponía unos conocimientos de carácter teórico - práctico claves para reconfigurar unos esquemas de comportamiento y de pensamiento necesarios para participar activamente en la vida social. “La educación fundamental es por lo tanto educación social por excelencia; es organización y transformación de la comunidad como exigencia de la integración sociocultural. Es capacitación de la persona social y del grupo para que por sí mismos mejoren sus condiciones de vida, mediante esfuerzo propio y ayuda mutua". ${ }^{113}$ Esta organización y transformación solo se podría llevar a cabo por medio del conocimiento de las características fundamentales de la vida social del individuo. Así la acción cultural se haría evidente, en tanto los cambios se dieran en el ámbito individual y en el colectivo a partir de la interacción con los otros, modificando y socializando actitudes, comportamientos y valores sociales.

Para Gustavo Pérez, la labor desarrollada por Acción Cultural Popular en este sentido se estaba planteando una movilización ideológica que tenía que ver con la necesidad de "abrir las mentalidades a la idea del bien común, a los criterios de eficiencia y de productividad. Hay que orientar al colombiano hacia nuevos modos de pensar y de obrar que permitan una integración social y económica"114. Afirmaba que era indispensable una acción integral que estuviera orientada a crear nuevas formas de pensar, de vivir y de obrar para que las transformaciones sociales pudieran ser duraderas en el tiempo y en la sociedad.

Para Pérez, el tema de la instrucción escolar de los niños campesinos debía estar dirigido al papel que desempeñarían estos en su vida y en sus labores cotidianas, por lo tanto era necesaria la "especificidad de la educación rural, no solamente para segurar el acceso de los campesinos a la instrucción superior, sino también para dar a la instrucción su función social, y al trabajo agrícola su calificación propia”. ${ }^{115}$

Las Escuelas Radiofónicas se convirtieron en la célula vital del movimiento radiofónico que relacionó lo teológico, lo sociológico y lo educativo, en un escenario común que era eminentemente pedagógico. A partir de la enseñanza de unos conocimientos básicos se impactaba en los tres ámbitos mencionados.

113. HOUTART, Francisco y PÉREZ, Gustavo. Acción Cultural Popular. Sus principios y medios de acción, op cit., p. 44. 114. PÉREZ, Gustavo. El Campesinado Colombiano...p. 189

115. Ibid., p. 198 
En la Educación Fundamental Integral no se utilizaron términos como asignaturas o materias de estudios para llamar a esos contenidos básicos, sino que se utilizó el concepto de nociones, entendido como una serie de ideas, contenidos y prácticas educativas, que llevaban a la generación de unas pautas de pensamientos, a unas actitudes y a unas formas de comportamiento, que favorecían la generación de unas competencias que permitieran la solución de necesidades. Houtart y Pérez afirmaban que la educación fundamental contribuía eficazmente al desarrollo de la sociedad, porque

...la acción sobre la escala de valores despierta la conciencia de la persona humana y desarrolla el sentimiento de solidaridad, con lo cual sienta las bases para una organización social, en la que tanto las personas como los grupos ocupen su sitio y desempeñen su papel; hace posible una vida cultural por su acción sobre las mentalidades y comportamientos, y culmina finalmente en la integración sociocultural. ${ }^{116}$

Desde esta visión, para asumir un papel en la vida social, el individuo necesitaba las nociones básicas de carácter teórico y técnico que le permitieran desempeñarse en grupo y en la sociedad, ajustándose a los esquemas de pensamiento y de comportamiento de acuerdo con su función social. El aprendizaje de los esquemas y comportamientos lograban una participación constructiva del individuo en la vida social. Se entendía que a partir de estas nociones el campesino lograría mantener su libertad y construir o proyectar su personalidad, sin caer en alienaciones de tipo ideológico o sin que coartaran su voluntad. Las Escuelas Radiofónicas, desde sus primeros años y antes de consolidarse el concepto de Educación Fundamental Integral, ya se habían convertido en un medio para prevenir el ingreso de ideologías no deseadas. En este sentido se expresa el informe de ACPO a la Conferencia Episcopal de 1955:

El fenómeno del crecimiento al que aludíamos arriba también explica la necesidad de prevenir al campesino contra corrientes determinadas, necesidad claramente apreciada por muchos párrocos del país, que han visto en las Escuelas Radiofónicas una barrera contra la infiltración de ideologías extrañas ${ }^{117}$.

116. Ibid., p. 44.

117. Informe al Eminentísimo señor Cardenal y a los Excelentísimos prelados de Colombia reunidos en Conferencia Episcopal en 1955. Acción Cultural Popular. Escuelas Radiofónicas. p. 3. 
La Educación Fundamental era una educación social, pues buscaba la organización y transformación de la comunidad con el interés de lograr una integración sociocultural. La capacitación de la persona social y del grupo llevaba a que se mejorara las condiciones de vida, mediante el esfuerzo propio y la ayuda mutua. La concepción de educación fundamental partía del principio de que el hombre estaba ubicado en un mundo lleno de potencialidades que le permitía transformarlo y utilizarlo para satisfacer las necesidades. ${ }^{118}$

Para Acción Cultural Popular, el desarrollo se lograba a partir de un trabajo organizado, descubriendo las potencialidades de los grupos sociales. Y para ello, la metodología de iniciación para el cambio era por medio de la Educación Fundamental Integral. ACPO consideró que los cambios que se hacían a partir de modelos como el propio eran más racionales, más constructivos y, aunque tal vez más lentos, menos devastadores que los cambios revolucionarios, que implicaban violencia y un presupuesto de que todo lo tradicional debía ser sustituido. Para ese momento ya había llegado al poder Fidel Castro, después del triunfo de la revolución cubana y el derrocamiento de Fulgencio Batista en la Isla. Fidel Castro, por medio de la vía revolucionaria, hizo cambios significativos en temas como la educación, la distribución de la tierra y la salud. También Camilo Torres, el sacerdote colombiano que posteriormente se conoció como el "cura guerrillero", en un estudio que hizo sobre ACPO, criticaba la falta de decisión de la institución para romper con las viejas estructuras establecidas para generar cambios rápidamente y cambios duraderos. Torres afirmaba que el descontento de las poblaciones rurales "podría llevar a un estado revolucionario violento, ya que este se produce cuando las necesidades sentidas no encuentran cauces de solución pacífica". ${ }^{119}$

La Educación Fundamental Integral era entendida como un proceso dinámico que operaba en todas las actividades de la vida humana, puesto que a partir del contenido de las nociones el hombre asumía consciente, libre y responsablemente su tarea en la promoción del desarrollo. Es decir, mediante esta educación fundamental se enseñaba a vivir, a participar en sociedad y a participar en la solución de los problemas. Este tipo de educación buscaba cubrir todos los campos donde se desarrollaba la actividad de la persona, además de incluir todo el espectro de las necesidades tanto materiales como biológicas, entre ellas aspectos como la alimentación, el vestido, la vivienda y la salud, entre otros.

118. BERNAL, Hernando. "Radio educativa para el desarrollo rural: el precursor Radio Sutatenza y Acción Cultural Popular, su influencia en la región", en Radio y democracia en América Latina. IPAL - Instituto para América Latina, 1989. p. 94.

119. TORRES, Camilo y CORREDOR, Bertha. Las Escuelas Radiofónicas de Sutatenza - Colombia, Bogotá, Centro de Investigaciones Sociales. 1961. p. 53. 
Esta educación estaba relacionada con todos los aspectos atinentes a la vida del hombre. Por ser integral no solo reparaba en los aspectos de tipo material, sino que incluía la vida intelectual, la vida social, y en general la globalidad de los problemas humanos. Una educación necesaria para aquellos que por su situación estructural se encontraban aislados de los beneficios y los servicios que producía la sociedad.

Pero la Educación Fundamental Integral se debía caracterizar en hechos concretos. Era necesaria que su efectividad fuera verificable. El aprendizaje de conocimientos y técnicas debía convertirse en hechos de manera consciente mediante su aplicación, creando costumbres y nuevos hábitos sociales. Es decir, se esperaba que el campesino, al aprender a leer, ejercitara su aprendizaje leyendo el periódico que lo vinculaba con la vida nacional, o libros que le permitían acceder a nuevos aprendizajes. 0 si aprendía los números, empezara a llevar con claridad y prontitud su presupuesto familiar, midiendo así sus ingresos y sus gastos. ${ }^{120}$

Por medio de las Escuelas Radiofónicas, la Educación Fundamental Integral llevó al campesinado los conocimientos elementales y los combinó con aprendizajes de asignaturas complementarias. Como la gran mayoría de campesinos no habían tenido la oportunidad de asistir normalmente a la escuela, en ACPO recibieron la educación básica y otros conocimientos que le aportaban a mejorar su calidad de vida. El ingreso del campesino a estos procesos educativos era voluntario, pero debían ser parte de una acción responsable y constante. Los estudiantes podían matricularse en las Escuelas Radiofónicas con absoluta libertad y podían, igualmente, suspender en el momento que lo quisieran, pero debían tener en cuenta que el proceso requería de responsabilidad, entendida esta como el cumplimiento de los compromisos adquiridos a la hora de obtener su radio por medio de créditos para pagarlo por cuotas, y también la responsabilidad con su comunidad a la hora de llevar a cabo obras de mejoramiento.

Pero si la idea era que el campesino mejorara su propio entorno y aportara en la solución de sus propios problemas, surgía un interrogante que consistía en determinar cuáles eran las necesidades de ese campesinado al que se le estaba llegando mediante las clases radiales. ACPO respondió a este interrogante trabajando con aquellas personas que hacían parte de las diferentes Escuelas Radiofónicas. "Por medio de la observación participante, los iniciadores del trabajo de las Escuelas Radiofónicas obtuvieron un conocimiento de primera mano sobre

120 Radio Sutatenza, 60 años de un sueño. Curso básico. Ejercicios para leer de corrido y escribir, Radio Nacional de Colombia. 2008. 
las realidades de la vida de los hombres del campo". ${ }^{121}$ Posteriormente el periódico El Campesino realizó encuestas preguntando a la población campesina cuáles eran los principales problemas que tenían.

El carácter polifacético del hombre incluía necesidades en diferentes ámbitos; estas giraban en torno a valores individuales y sociales que comprendían lo físico y mental, lo sicológico, lo social, lo cultural y lo moral. ${ }^{122}$ De allí surgió la necesidad de suministrar a los campesinos formación en cinco aspectos que constituyeron la Educación Fundamental Integral y que se hicieron visibles con las diferentes nociones: Alfabeto, Número, Salud, Economía y Trabajo (Agricultura), y Espiritualidad. Estas nociones hicieron parte de una propuesta que establecía una relación entre la educación fundamental, el uso de los medios y el énfasis didáctico por medio de las cartillas. A esta propuesta se le denominó Operación Cinco. ${ }^{123}$

\section{Las nociones de la Educación Fundamental Integral}

Las cinco nociones de la Educación Fundamental Integral de ACPO fueron propuestas a partir del análisis de las necesidades de los campesinos. A continuación se explicará cada una de las nociones con sus contenidos generales y los objetivos propuestos.

ACPO, como institución de la Iglesia, consideró de especial importancia la Noción de Espiritualidad, puesto que la acción educativa de las Escuelas Radiofónicas debía girar en torno a la escala de valores del hombre, logrando que este tomara conciencia de los valores fundamentales, de su condición de "ser creado, elevado a un estado sobrenatural, partícipe de la vida misma de Dios y miembro de la comunidad de hermanos". ${ }^{124}$ ACPO pretendía dar una educación al campesinado que le permitiera mediante el ver, el juzgar y el actuar, incidir en su entorno, guiado por la doctrina de Cristo.

A partir de la noción de Espiritualidad se planteó la necesidad de que el hombre luchara por la salvación eterna y por el mejoramiento de las condiciones de

121. BERNAL, Hernando, Educación Fundamental Integral. Teoría y aplicación en el caso de ACPO. Bogotá, Editorial Andes, 1978. p. 132.

122. Informe a la Venerable Conferencia Episcopal, 1961 a 1964, Bogotá. p. 63.

123. Ibid.

124. HOUTART, Francisco y PÉREZ, Gustavo. Acción Cultural Popular. Sus principios y medios de acción, op cit., p. 45. 
vida, porque Dios deseaba el bienestar individual y social del hombre durante su permanencia en la tierra. Igualmente, toda acción del hombre estaba influenciada por la gracia de Dios. Pero la responsabilidad de los actos humanos era individual y por eso a cada persona le correspondía hacer todo lo posible para mejorar sus condiciones de vida, para lo cual debía trabajar y asociarse.

Pero esta noción no solo hacía parte de la vida religiosa, de lo espiritual, sino que iba más allá, ubicándose también en las relaciones sociales y personales del ser humano, en este caso del campesino. Se planteaba de esta manera la idea de que Dios traspasaba todos los límites y deseaba el bienestar del hombre en todos sus ámbitos.

El desarrollo del hombre no era solo una opción personal e individual, sino que para salir del subdesarrollo era necesario utilizar las potencialidades que habían sido dadas por Dios. Alcanzar la gloria y cumplir la misión impuesta por Dios, incluía un deber social y un deber de solidaridad que conjugaba perfectamente con el papel que debían cumplir todas aquellas personas que hacían parte de las Escuelas Radiofónicas. Los deberes de los campesinos, en este caso, estaban en función de lo público y de la misma Iglesia Católica. Cada una de las acciones de carácter individual, llevadas a cabo en las Escuelas Radiofónicas, debía estar al servicio de la comunidad.

En la relación entre la fe y el desarrollo, ACPO sostuvo como principio ideológico el deber de la sociedad y de la Iglesia para colaborar en el desarrollo de los valores espirituales, culturales, sociales y familiares "y aún de perfección individual que Dios ha puesto en cada uno de los hombres como semilla que habrá de fructificar según la naturaleza y el Plan Creador..." ${ }^{125}$ Es así como alfabetizar al pueblo, colaborar en el mejoramiento de la producción agrícola y elevar el nivel de vida de los hombres, respondía a las exigencias fundamentales del Señor y a la indisoluble unión entre acción terrenal y la acción espiritual. De esta manera, ser parte de la obra de ACPO significaba ser parte de la Iglesia. Pero así mismo, para ser parte de la Iglesia se debía ser parte de la obra de Acción Cultural Popular. Esta noción enmarcaba la acción de las personas dentro del ámbito solidario de la acción comunitaria, desarrollando valores de solidaridad necesarios para poder existir en comunidad.

125. HOUTART, Francisco y PÉREZ, Gustavo. Acción Cultural Popular. Sus principios y medios de acción, op cit., p. 14. 
Las clases que hacían parte de esta noción dentro de la programación de las Escuelas Radiofónicas eran de catecismos, de formación, de lo que se debe saber y practicar, y de orientación de la vida familiar y social.

La noción Salud era entendida como la condición para la plena expansión de las facultades físicas e intelectuales del hombre. Esta noción estaba inspirada en los planteamientos de la Organización Mundial de la Salud que afirmaba que "La salud es el estado de completo bienestar físico, mental y social y no solo la ausencia de enfermedad o invalidez". ${ }^{126} \mathrm{El}$ cuidado del cuerpo surgía con esta noción como un deber cristiano, personal y social. Se impartía mediante clases de higiene mental, higiene corporal, de higiene ambiental, de nutrición, de prevención de enfermedades y accidentes, de primeros auxilios y botiquín familiar, de puericultura y de campañas sanitarias. Por medio de ella se desarrollaba una actividad de previsión y conservación del ambiente y de los individuos.

La noción Alfabeto era considerada como la puerta de acceso hacia la cultura, al progreso técnico y el contacto con la sociedad. Mediante el acceso a la lectura y la escritura se le facilitaba al campesino su entrada al mundo intelectual, espiritual, social y económico, y se lograba mejorar el intercambio cultural y social. ACPO consideró que la enseñanza del alfabeto era indispensable como conocimiento básico para mejorar la participación de los estudiantes en sus relaciones sociales, en la organización social y en la vida cultural. La tarea alfabetizadora de ACPO se llevó a cabo desde los inicios de Radio Sutatenza. Adquiriendo este conocimiento los campesinos lograban ampliar los demás conceptos de la educación integral. Era fundamental el leer y escribir para acceder a los diferentes contenidos dados a través de los cursos radiales.

El aprendizaje de la lectura y la escritura llevó a ACPO a la adopción de un método que, en los primeros años, consistió en el uso de otro medio como los afiches para acompañar los programas radiales; ${ }^{127}$ posteriormente se incluyó el acompañamiento de un medio humano, como los auxiliares inmediatos; y por último la elaboración de una cartilla que acompañaba las clases radiales del alfabeto. Las clases eran de lectura y escritura, de orientación para el uso del periódico, de orientación para el uso de la biblioteca, y de campañas de alfabetización. Para fortalecer el aprendizaje de esta noción, ACPO publicó el semanario El Campesino y

126. Ibid., p. 46.

127. La revisión del archivo de Sutatenza permitió ver cómo en las clases que se daban a las primeras Escuelas Radiofónicas se utilizaron los afiches como un medio auxiliar para el aprendizaje. 
organizó la Biblioteca del Campesino, ${ }^{128}$ que contaba con varios títulos y cuyos libros eran enviados a las diferentes Escuelas Radiofónicas. Hasta el 31 de diciembre de 1967, ACPO había impreso 12 títulos diferentes de la Biblioteca del Campesino; entre ellos estaban La buena nueva (el Evangelio según San Lucas), El Evangelio de San Mateo, La madre y el niño, Primeros auxilios, Verduras y frutas, Juegos y diversiones, Cooperativa de ahorro y crédito, Chispa y buen humor o ¡Qué bueno ser colombiano!, entre otros.

Para ACPO existía una gran falla en la cultura del pueblo colombiano, pues el valor del Número no estaba apropiado por las personas y como consecuencia de esa falencia se ignoraba el rigor del cálculo y de la previsión. Dentro del modelo de Educación Fundamental Integral, la noción Número buscaba que el campesino se familiarizara con los conceptos de tiempo y espacio, que le permitirían comprender la relación hora de trabajo con productividad. Además, esta noción buscaba que los campesinos pudieran planear y contabilizar sus gastos y sus ingresos. El conocimiento de las matemáticas también permitía que los campesinos accedieran con mayor tranquilidad a los préstamos y pudieran calcular sus pagos.

Una última noción dentro del modelo de Educación Fundamental Integral tenía que ver con Economía y Trabajo. Esta noción entendía el trabajo del hombre como el desarrollo de las capacidades creativas del mismo con la idea de lograr progreso. ACPO en esta noción realizó un esfuerzo educativo dirigido hacia el trabajo agrícola, pero consideraba que dentro de la propuesta los contenidos de esta enseñanza cambiarían, puesto que la tecnificación de la agricultura llevaría a disminuir la proporción de personas que debían trabajar en el campo. La liberación de la fuerza de trabajo pasaría a otros sectores y necesitaría de unos conocimientos diferentes, por eso ACPO pensó que la formación hacia el futuro debía ser politécnica, con el fin de capacitar al hombre para los nuevos retos.

Esta noción cumplió un papel importante, pues por medio de ella se intentó impactar en las estructuras agrarias, dando a conocer y ayudando a comprender al campesinado los valores fundamentales sobre el problema económico, social y técnico, de la agricultura. Con la perspectiva de cambiar dichas estructuras agrarias, educacionales y sociales, se dieron "al campesino los fundamentos de la economía y de la técnica agrícola, cubriendo todo el ciclo de la producción, del mercadeo y del consumo e insistiendo en las implicaciones sociales y laborales

128. ACPO editaba y distribuía los libros de la Biblioteca del Campesino. Los lectores adquirían el libro a cambio de un huevo. Hasta el año de 1967, según el informe enviado a la Venerable Conferencia Episcopal, se habían impreso 12 títulos diferentes. 

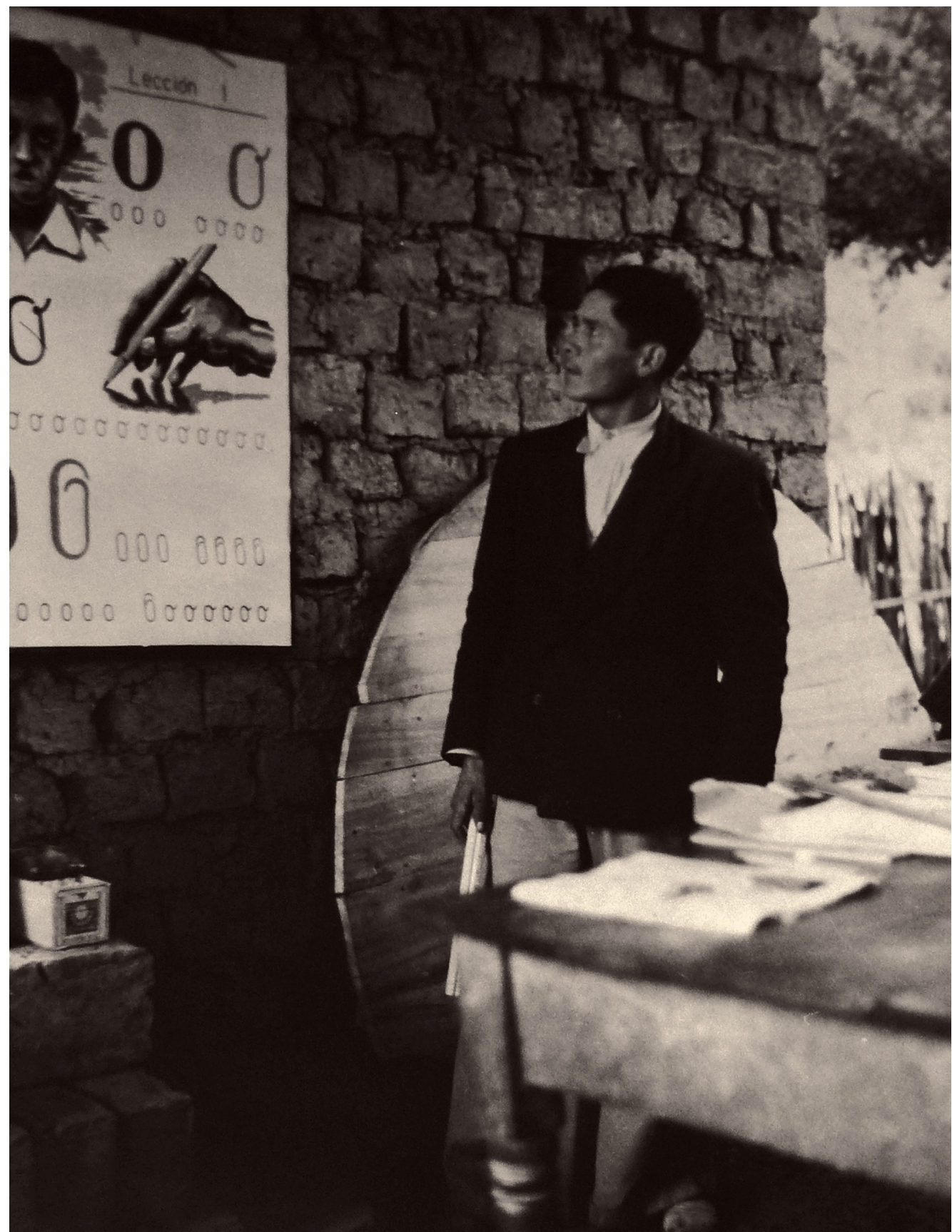
de la agricultura". ${ }^{129}$ Las clases que hicieron parte de esta noción fueron, entre otras: la defensa del suelo, defensa de las plantas, técnica de cultivos, huerta casera, jardinería, industrias animales (vaca de leche, cerdo, gallina, abeja, etc.), y economía doméstica (culinaria, modistería y bordados, etc.).

\section{Los elementos o medios de acción}

A partir de la definición de las nociones había que hacer la conversión de estas a cartillas, pues la Operación Cinco planteaba como propósito “el hacer que en el menor tiempo posible, el mayor número de campesinos posea y ame las cinco cartillas, síntesis de las nociones básicas de educación integral cristiana; que las aprenda y las practique para incorporarse conciente y libremente a su propio mejoramiento y al progreso de la patria". ${ }^{130}$ Esto implicaba un impulso a los denominados elementos de acción como la misma radio, las cartillas, el periódico, la biblioteca, la correspondencia, los institutos campesinos, los cursos de extensión y las grabaciones.

Desde 1960 y durante algunos años fue difundido un diagrama en el periódico El Campesino, de documentos de trabajo y de carteles donde se podía ver los aspectos centrales y distintivos del modelo educativo de ACPO. Este incluía las nociones mencionadas, los medios de acción utilizados y la organización regional y local de ACPO, estrechamente ligada a la formación de líderes y dirigentes campesinos y al posicionamiento de los Auxiliares Inmediatos como sujetos claves en la organización de las Escuelas Radiofónicas y de la institución en general. ${ }^{131}$

Como se observa en el diagrama de la página 80 , el modelo educativo no solo apuntó a llevar unas clases por medio de la radio, sino que se constituyó en un proyecto multimedial, es decir, que utilizó simultáneamente varios instrumentos de comunicación para optimizar el proceso de aprendizaje. Si bien inicialmente se pensó que la labor pedagógica tenía como su medio principal las clases radiales, las Escuelas Radiofónicas con la Educación Fundamental Integral eran mucho más que transmitir contenidos por la radio. Los otros medios no solo fortalecieron el proceso de enseñanza y aprendizaje, sino que se fueron convirtiendo en determinantes. Es así como en el diagrama se observa a la totalidad de los medios en una misma línea horizontal. Se utilizaron diferentes medios con el objetivo de

129. HOUTART, Francisco y PÉREZ, Gustavo. Op cit. p. 50.

130. Informe a la Venerable Conferencia Episcopal, 1961 a 1964, Bogotá. p. 63.

131. El Campesino, Bogotá, 27 de noviembre de 1988, p. 7. 
llegarle al campesinado con una educación que le aportara y le ayudara a mejorar sus condiciones de vida. Mencionaremos algunos de ellos, especialmente los más reconocidos, y analizaremos el papel que cumplieron dentro del sistema de la Educación Fundamental Integral.

Así como los medios se complementaron, la Educación Fundamental Integral no tomaba cada una de las nociones como una respuesta individual a las necesidades, sino que se constituían en un entramado que en su totalidad aportaban a la búsqueda de soluciones del campesino.

De esta manera, mientras que el profesor de la noción Alfabeto utilizaba la palabra leche para enseñar la e o la ch, al mismo tiempo dejaba claro el valor nutritivo de este alimento y motivaba a los estudiantes para que trataran de hacer el esfuerzo de tener una vaca lechera. Así, a partir de varios conceptos que se trabajan en la noción Alfabeto se relacionaban con el resto de las nociones como el Número o la Salud, entre otros. Otro ejemplo se presenta con la noción Número; en esta clase se hacían ejercicios para medir el área de la casa del campesino, pero aparte de practicar la aritmética, se mostraba en las cartillas una organización y distribución de la vivienda campesina, así como la ubicación de los sitios relacionados con la higiene. ${ }^{132}$

Las cartillas como uno de los medios de acción ya habían sido utilizadas en los primeros años de las Escuelas Radiofónicas, pues el Ministerio de Educación del gobierno de Laureano Gómez, realizó una donación de las cartillas que se utilizaban para los niños en las escuelas. ${ }^{133}$ Como dicho material no estaba dirigido al estudiante campesino, ACPO recibió la asistencia de expertos en textos escolares de la Unesco, quienes durante cuatro años trabajaron en la preparación y validación de la primera cartilla de lectura, escritura y aritmética como elementos complementarios de la educación impartida por los profesores radiofónicos.

El 14 de octubre de 1953, la UNESCO inició un programa de asistencia técnica a ACPO. Consistió en la visita de una comisión compuesta por el doctor Adishesha, de nacionalidad hindú, y los hermanos cristianos Idinael y Fulgencio. Idianael, de origen francés, experto en textos escolares, y Fulgencio, español, técnico en ilustraciones de textos. 


\section{ACCION CULTURAL POPULAR}
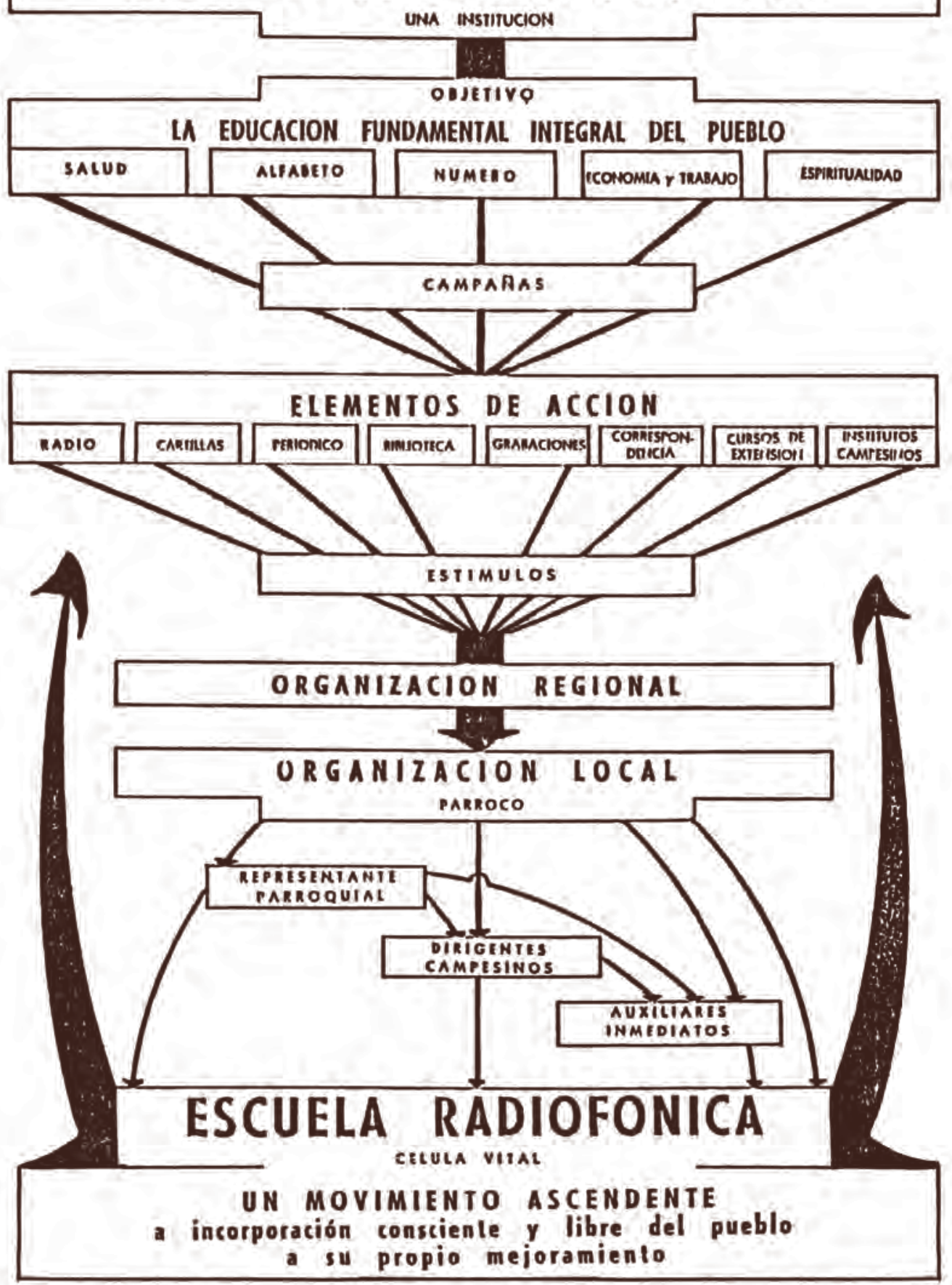
De acuerdo con sus estudios e investigaciones se decidió preparar y experimentar la primera "Cartilla de Lectura" y diseñar las láminas de lectura, escritura y aritmética, en razón de que este tipo de materiales, por ser de índole visual, complementaban la parte meramente auditiva de la radio, que ya había comenzado a actuar en labores culturales Dicha asistencia técnica se prolongó hasta 1957. ${ }^{134}$

En 1955 ya se habían distribuido 82.292 cartillas de una impresión total de doscientos mil, que iban dirigidas a los estudiantes que escuchaban sus clases en los equipos de recepción que tenían 129 parroquias. Para ese año, el padre Salcedo afirmaba contar con la colaboración de 601 parroquias de las 983 existentes en las zonas rurales del país. ${ }^{135}$

La cifra de campesinos alfabetizados en la primera década de funcionamiento de ACPO legitimó el uso de las cartillas como un medio de acción. Desde 1948 hasta 1957, la institución contaba con un total de 21.990 estudiantes alfabetizados en lectura y escritura, y con 62.283 con conocimientos básicos de economía rural, es decir, aprendizaje de la aritmética. El crecimiento de estudiantes fue especialmente significativo a partir de 1955, cuando las Escuelas Radiofónicas pasaron de tener 87.064 estudiantes a 145.114 en $1958 .{ }^{136}$

Ante los hechos, las cartillas se constituyeron en un medio indispensable dentro de la formación de los campesinos que hicieron parte de las Escuelas Radiofónicas y que recibieron la Educación Fundamental Integral. Los campesinos utilizaron las cartillas para realizar los ejercicios prácticos que eran asignados durante la emisión de las clases radiales. ${ }^{137}$

Las clases en las Escuelas Radiofónicas se emitían en diferentes horarios, según la publicación de una programación en el periódico El Campesino; se realizaban emisiones de las clases de lectura y escritura de lunes a jueves con una duración aproximada entre 12 y 16 minutos. Estas clases hacían parte de la educación básica y salían al aire de 6 a.m. a 6:25 a.m., con repetición a las 3 de la tarde. A las 6:44 a.m. hasta las 7:00 a.m. estaban las clases de aritmética y catecismos durante tres días, turnándolas días de por medio. El resto de los cursos que tenían que ver

134. El Campesino, Bogotá, 12 de septiembre de 1976. p. 6.

135. Informe al Eminentísimo señor Cardenal y a los Excelentísimos prelados de Colombia reunidos en Conferencia Episcopal en 1955. Acción Cultural Popular. Escuelas Radiofónicas, p. 3.

136. Informe a la Venerable Conferencia Episcopal, 1957 - 1958, Bogotá, p. 8.

137. Las cartillas correspondientes a las cinco nociones establecidas fueron editadas en 1962. El Campesino del 1 de julio de 1962 reseña dicha información y da a conocer algunas opiniones al respecto. 
con las otras nociones eran dados entre las 6:25 y las 6:42 de la mañana. Estos cursos los realizaban uno o dos locutores, quienes a medida que iban explicando, daban instrucciones para ir guiando al estudiante. Igual que las clases de lectura y escritura, todas las demás se repetían en las horas de la tarde para que el alumno pudiera acceder a ellas en cualquiera de los dos horarios.

La programación hacia finales de los años 50 contaba con 13 contenidos diferentes. Entre ellos estaban los concernientes a las nociones básicas de la Educación Fundamental Integral, y algunos otros programas como eran los boletines informativos, los dramatizados o los programas de música y variedades.

En cada una de las Escuelas radiofónicas había una persona, denominada Auxiliar Inmediata, que ayudaba a los campesinos estudiantes con el aprendizaje de los conocimientos transmitidos a través de la radio. Este auxiliar inmediato se constituyó en pieza fundamental dentro del engranaje, pues era quien debía matricular a los estudiantes de su escuela e informar sobre ella, conseguir los útiles escolares solicitándolos en la parroquia, seguir las clases, cumplir lo que le pedía el profesor por la radio y apoyar a los estudiantes en la adquisición de los conocimientos impartidos. ${ }^{138}$ Este Auxiliar no necesariamente era un profesor, sino que bastaba con que tuviera algún grado de educación formal, preferiblemente que hubiera terminado la escuela primaria y que tuviera el deseo de ayudar a sus familiares o a los miembros de la comunidad. El padre jesuita, Francisco Javier Mejía, lo describe como "un campesino como los demás, pero con algunas nociones rudimentarias de estudio y de conocimientos de lectura y escritura, amén de una buena dosis de abnegación y un chispeante entusiasmo por la obra". ${ }^{139}$

Los Auxiliares Inmediatos no solo contaron con el apoyo de las cartillas, sino que también utilizaron el semanario El Campesino, que empezó a circular desde junio de 1958 como un periódico "al servicio y en defensa de los campesinos". ${ }^{140}$ Los fines de esta publicación, según el mismo semanario, eran básicamente dos:

- Contribuir a la revalorización de la vida rural, por parte de los campesinos en primer término, y de las otras clases sociales, con un concepto cristiano del trabajo del campo;

- Servir de complemento a la obra en que está empeñada la Iglesia con la organización de las Escuelas Radiales.141

138 El Campesino, Bogotá, 4 de febrero de 1968, p. 5.

139 Revista Javeriana, No. 160, noviembre de 1949, p. 288.

140 El Campesino, Bogotá, 29 de junio de 1958.

141 Ibid., p. 2. 


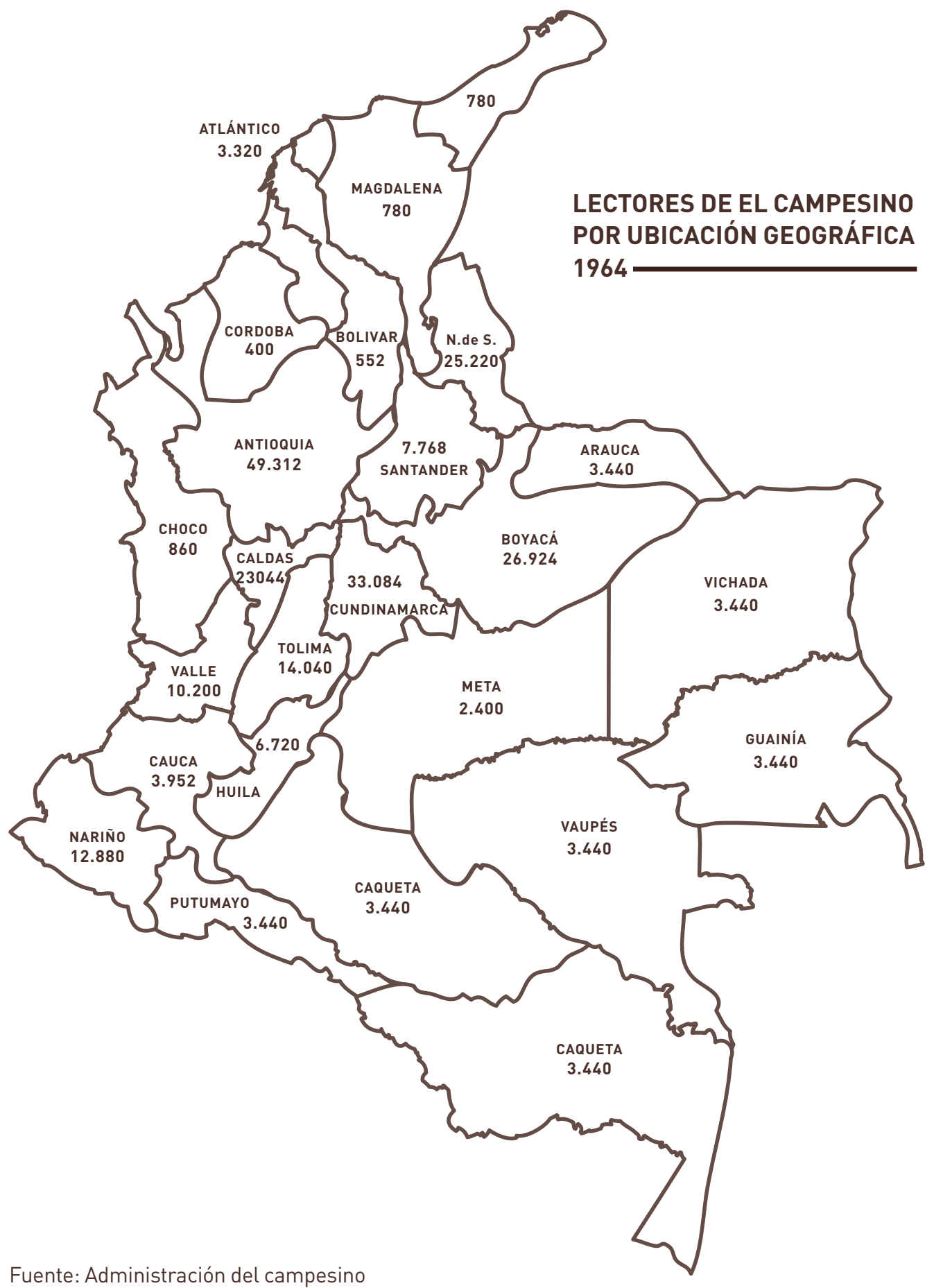


El apoyo prestado por este semanario en el sistema de la Educación Fundamental Integral tomaba dos vías; una, que tenía que ver concretamente con la formación de los conocimientos básicos del campesino, puesto que la adquisición del diario podía fortalecer el aprendizaje de la lectura; y otra, que permitía al campesino relacionarse con el mundo exterior a través de este medio de comunicación. El Campesino era un mediador entre una clase excluida tradicionalmente de las decisiones y las clases dirigentes del país.

Desde sus primeras ediciones, este semanario recogió temas de interés para el campesinado reivindicando el uso racional de la tierra, el derecho a una vida digna, la búsqueda del bien común y la defensa de la vida social, del desarrollo de la parroquia rural y del progreso. La pretensión del periódico era "Transformar al hombre, valorizar todas su posibilidades individuales y colectivas; reestructurar la sociedad en Cristo", considerada como "la amplia empresa que acomete este semanario en un mundo donde los hombres se asfixian de egoísmos". ${ }^{142}$

La vinculación directa del periódico El Campesino con las Escuelas Radiofónicas garantizó en buena medida la adquisición del mismo, por eso el tiraje anual aumentó considerablemente. Lo que empezó en 1958 con una circulación de 29.800 periódicos, alcanzó en 1963 un total de 80.563 periódicos semanales.

El número de páginas de este semanario estuvo entre 16 y 20, y estaba conformado por tres secciones fijas: una, de información general y orientación editorial, es decir, páginas que recogían información de todo el país sobre temas relacionados con la economía, la política, o los hechos internacionales; otra, de servicios y divulgación y conocimiento de nuevas técnicas, que informaba sobre servicios que prestaban organizaciones como el ICA o la Caja de Crédito Agrario, además de publicar las nuevas técnicas para mejorar los cultivos o la cría de ganado; y la tercera, de variedades y desarrollo, que consistía en la divulgación de campañas para el mejoramiento de ambientes familiares. Esta última sección era producida en un $80 \%$ por los propios campesinos, mientras las otras dos eran elaboradas por redactores de planta y colaboradores permanentes. El Campesino llegó a tener corresponsales en 19 ciudades y en 722 poblaciones. ${ }^{143}$ Las secciones que hacían parte del periódico muestran un esfuerzo de este por llegarle a un gran número de personas en diferentes sectores. Aunque el periódico estaba dirigido hacia los campesinos, también, como se mencionó, abordaba temáticas que tenían que ver con las decisiones tomadas en las grandes ciudades del país o los hechos sucedidos a nivel nacional e internacional.

$142 \quad$ Ibid., p. 2 .

143 Informe a la Venerable Conferencia Episcopal, 1961 a 1964, Bogotá. p. 32. 
Durante los primeros años, el periódico tuvo varios cambios tanto en su formato como en sus colores y en el tamaño de letra. Dos años después de su fundación, el periódico amplió su formato de tabloide a universal y empezó a trabajar varias páginas con cuatro colores. La publicidad que hizo presencia en las páginas del periódico, inicialmente tenía que ver con la labor desarrollada por ACPO y muy especialmente por las Escuelas Radiofónicas, pero posteriormente se amplió con la vinculación de empresas como Seguros Bolívar, chocolate Corona o cigarrillos Pielroja, entre otros, quienes pautaban constantemente. Algunos programas de Radio Sutatenza eran patrocinados y por eso aparecían también avisos en el periódico como el publicado en 1960, donde con el logo de Texaco decía: "Radio Sutatenza invita a Uds. a escuchar los siguientes programas patrocinados por Texas Petroleum Company", y a continuación estaban los horarios de los programas culturales. ${ }^{144} \mathrm{~A}$ medida que el periódico alcanzó mayor presencia nacional, la publicidad aumentó. Igualmente, la vinculación de ACPO con instituciones del Estado permitió que ellas pautaran para promocionar o divulgar sus servicios. Ese fue el caso del ICA, del Incora y de la Caja de Crédito Agrario. ${ }^{145}$

El periódico se convirtió, para el campesinado que estaba en las Escuelas Radiofónicas, en una guía que podía ser leída, estudiada, repasada, coleccionada y consultada con frecuencia. Gracias a este medio hacía seguimiento de los aprendizajes con ejercicios adecuados y actualizados, puesto que su circulación semanal le permitía imprimir nuevos contenidos que no estaban en las cartillas, complementando y actualizando los conocimientos del mensaje educativo y las acciones de la Escuela Radiofónica.

El Campesino era un vehículo destinado a promover los cambios de actitudes, mentalidad y comportamiento utilizando mensajes persuasivos, dentro de lo que ACPO consideraba como el desarrollo integral de los individuos. Por ejemplo, el 3 de agosto de 1958, el semanario publicó un aviso donde enunciaba algunas de las virtudes que debía tener un pueblo:

Nuestro pueblo debe tener todas las virtudes cívicas, sociales y religiosas que hacen grande la vida de comunidad, pero de modo especial debe distinguirse por:

- La cultura de todos sus habitantes.

- El interés de todos por su progreso

- La unión de todos sus moradores. 
- La amabilidad, la gentileza y las buenas maneras para con los habitantes.

- El cumplimiento de los deberes cívicos.

- La preocupación por la educación de la niñez.

- El apoyo a las iniciativas provechosas para toda la ciudadanía.

- La colaboración al mejoramiento de los servicios públicos.146

Del mismo modo, continuamente hacía campañas que eran publicadas en el periódico donde invitaban al campesinado para que mejorara sus viviendas, sus huertas, sus gallineros o se implementaran los servicios de acueducto y alcantarillado en sus hogares. Estas campañas se hacían generalmente en homenaje al Papa, como la publicada el 24 de enero de 1960, que se titulaba “En este año, homenaje de las Escuelas Radiofónicas a su Santidad Juan XXIII, las comunidades parroquiales prestarán y ofrecerán sus realizaciones". ${ }^{147}$ De esta manera, el periódico, ante las limitaciones propias de la radio como el tiempo de las grabaciones o la imposibilidad de una interacción directa, complementaba a través de sus páginas con gráficas y con explicaciones detalladas de algunos temas.

El semanario dio cuenta de las informaciones que tenían que ver directamente con el campesino, con sus tierras, con la erosión o con la violencia que se manifestaba en diferentes zonas del país. En varias de las páginas de las diferentes ediciones, El Campesino publicó tanto noticias sobre lo que sucedía en las regiones del país, como información sobre los motivos generadores de violencia. El 20 de marzo de 1960 publicó un texto del obispo de la diócesis de Armenia, Jesús Martínez, donde afirmaba en este sentido que:

Todos estamos convencidos, agrega, de que entre los factores poderosos de la violencia, se cuenta la ignorancia religiosa en los diferentes campos sociales; por este motivo creemos que en la extinción de la violencia, la colaboración más efectiva de las autoridades diocesanas debe ser la de seguir intensificando, dentro de sus posibilidades, la más sólida instrucción religiosa de ricos y pobres, de niños y adultos, en todos los campos del apostolado. ${ }^{148}$

Pero no solo la falta de fe era considerada como generadora de la violencia; continuamente en el semanario se responsabilizaba al comunismo de la situación en la que vivía el país. En distintas ocasiones se escribieron en el semanario sobre el tema, titulares como "El comunismo fomenta la violencia en el Tolima"149 o

\footnotetext{
146 El Campesino, Bogotá, 3 de agosto de 1958.

147 El Campesino, Bogotá, 24 de enero de 1960.

148 El Campesino, Bogotá, 28 de marzo de 1960.

149 El Campesino, Bogotá, 7 de septiembre de 1958.
} 
“El comunismo respalda la violencia"150. Los artículos sobre el tema de violencia en el campo fueron recurrentes y aunque se hacía constante mención al comunismo, continuamente el periódico publicaba los hechos de violencia, la muerte de campesinos y los desplazamientos que se daban en diferentes regiones del país.

A pesar de esa situación social que se vivía en diferentes lugares de Colombia, el periódico mantenía su idea de dignificar al campesino, y por eso publicaba constantemente sobre el valor que tenía ser campesino. Por medio de diferentes artículos, el periódico resaltaba la labor de los campesinos, mostrándolos como unos seres de gran importancia para la economía del país, como hombres productivos, como campesinos cristianos y como hombres fieles al campo.

La imagen de campesino que ACPO buscaba proyectar era la de un ser que mantenía los rasgos de la vida rural, pero que lograba trabajar en comunidad para buscar el desarrollo de los pueblos. Un hombre que mediante la formación en las Escuelas Radiofónicas podía forjar su destino y el de su comunidad, trabajando para que las condiciones de vida mejoraran. La idea de la construcción de una nueva estructura rural estaba fundamentada según El Campesino en que la estructura se "levante" sobre "el respeto a la persona, sobre el respeto a la familia, sobre el respeto a la vida, sobre el respeto a la conciencia, sobre el respeto a la propiedad, sobre el respeto a la autoridad, sobre el desinterés cristiano, sobre la amistad sincera, sobre la confianza mutua". ${ }^{151}$ Es evidente que el concepto de respeto era fundamental en la formación de ACPO, pues por medio de él se podía generar unas condiciones que permitieran que el trabajo en comunidad se concretara con el diálogo y los acuerdos.

Los campesinos constantemente estaban siendo valorados en las páginas del semanario. Se aprecia el interés de ACPO por hacer que el campesino lograra sentir que se constituía en un hombre fundamental en la construcción del país. Uno de los avisos publicados mostraba al campesinado como la población más numerosa del país y la que más divisas producía, también como aquel grupo de hombres que más aportaba al Ejército para la defensa del territorio nacional. ${ }^{152}$

Por medio de sus páginas se difundían los avances y tareas que realizaban los campesinos a favor de su propio mejoramiento. Dentro de la idea de que este medio impreso era en defensa del campesinado, se hizo continua referencia al papel que

150. El Campesino, Bogotá, 17 de agosto de 1958.

151. El Campesino, Bogotá, 6 de julio de 1958.

152. Ibid. 
cumplía el periódico y ACPO a favor de los campesinos y la labor de monseñor José Joaquín Salcedo, dentro del marco de las funciones que tenía como director de la institución. En 1962, el semanario exaltaba la labor del mismo periódico:

En solo cuatro años de vida, EL CAMPESINO ha llegado a constituirse en el PRIMER órgano popular de su género con la MÁS ALTA difusión nacional y como el PRIMER semanario cultural de América Latina. Al educar, orientar el informar al pueblo, EL CAMPESINO está colocando a millones de colombianos en aptitud y capacidad de producir y consumir cada vez más cosas para vivir mejor.

Este triunfo es el resultado del entusiasmo y del sentido de solidaridad social de miles y miles de dirigentes y trabajadores de los pueblos y veredas del país que escriben ELCAMPESINO, que leen ELCAMPESINO, que distribuyen EL CAMPESINO, que difunden EL CAMPESINO y que en este semanario encuentran cada semana un estímulo para trabajar por su propia dignificación y por la grandeza y prosperidad de la nación a la que pertenecen. ${ }^{153}$

También se difundió información relacionada con las actividades de instituciones como el ICA, la Caja Agraria, el Incora y la Federación de Cafeteros, que prestaban servicios directos de créditos, capacitación, organización comunitaria y diferentes apoyos a la promoción de la salud y el mejoramiento de la vivienda. Varias de estas instituciones estatales cumplían papeles complementarios o similares a la acción desarrollado por Acción Cultural Popular, entonces para El Campesino era importante la publicación de las labores que desarrollaban, puesto que ellas intentaban beneficiar al campesinado. De otra parte, a ACPO le servía mantener unas relaciones directas con estas instituciones para, igualmente, contar con el apoyo de ellas en varios de los programas que llevaba a cabo. La Caja Agraria o la Federación de Cafeteros compraban espacios publicitarios en el semanario para promocionarse.

Varias de las publicaciones donde estaban vinculadas las instituciones mencionadas mostraban la relación existente entre sus programas y los proyectos que desarrollaba ACPO. Un ejemplo de ellos fue la financiación que realizó la Caja Agraria para que los campesinos pudieran obtener los radios que les permitían escuchar los programas producidos por la emisora Sutatenza. Bajo el título de 
“Entusiasmo por el nuevo servicio de la Caja Agraria", El Campesino explicaba el programa de financiación:

Han comenzado a llegar a nuestra redacción mensajes de varias comunidades rurales del país en los que se expresa el entusiasmo y reconocimiento por el programa de crédito de la Caja Agraria, mediante el cual los almacenes de Provisión Agrícola de esa entidad han comenzado a distribuir los radio receptores transistorizados que permiten al pueblo rural participar en los programas de Acción Cultural Popular para su mejoramiento.

Particular entusiasmo demuestran en los campos por las facilidades o plan de crédito para la cultura que ofrece ahora la Caja Agraria, mediante el cual se dan facilidades para que los habitantes de los campos puedan adquirir los receptores con una cuota inicial de 45 pesos y con plazo hasta de diez meses para pagar el valor total de este moderno medio de comunicación y educación. ${ }^{154}$

Otra de las secciones era la llamada correo campesino. Esta sección publicaba semanalmente las cartas de los oyentes y lectores del propio periódico. Eran cartas que tenían que ver con los temas tratados en las clases radiales o con aspectos relacionados con el campesinado. Cartas que tenían que ver con los servicios que prestaba la Caja Agraria, como la que escribió un campesino del Huila donde le hacía saber "al gobierno y a la opinión pública que tenemos necesidad de una sucursal de la Caja Agraria con su respectiva sección de ahorros en este pueblo" o las relacionadas, en el mismo periódico, con algunos de los aspectos de la Escuelas Radiofónicas, como el caso de un campesino de Antioquia, quien avisaba que si no había una rebaja en las pilas (baterías) de los transistores, se vería en la obligación de privarse de la Escuela.

Mis circunstancias económicas no me permiten seguir disfrutando de ese gran servicio, pues la pila hasta llegar a mí, me cuesta $\$ 48.00$, con $\$ 4.00$ que me toca pagar de transporte. Y si no tengo que pagar repuestos por daños en el receptor, ¿a cuánto se me eleva el costo de la escuela? Imposible, imposible. Mucho dolor me da tener que privarme de tan sabias enseñanzas, pero no alcanzo. ${ }^{155}$ (sic)

Las cartas de esta manera se convertían en el medio utilizado por el campesino para socializar sus problemas y para evidenciar las necesidades de su entorno. Las cartas 
que llegaban a ACPO, en relación con las Escuelas Radiofónicas eran respondidas de manera personal, pero aún así algunas eran publicadas en el periódico. De esta manera se hacía una socialización de los problemas del campesinado, pero también se destacaban aquellos escritos que tenían que ver con el trabajo desarrollado por las Escuelas Radiofónicas, por El Campesino y por ACPO en general. La publicación de cartas en este sentido era masiva y mayoritaria. Habitantes de todas las regiones del país enviaban estas cartas. Venían de municipios como La Calera, Sibaté o Tausa, cubrían desde el departamento de Boyacá y Cundinamarca hasta el Putumayo o la Guajira. Por ejemplo, del Norte de Santander un campesino enviaba una misiva donde destacaba la labor del periódico:

Respetuosamente me dirijo a ustedes enviándoles mi más efusivo saludo y para felicitarlos por su valiosa labor que han adelantado desde sus columnas a favor de la inmensa masa campesina del pueblo colombiano, con sus lecciones que trae cada semana, instrucciones y consejos, respuestas a sus preguntas y problemas que a diario presentan. ${ }^{156}$

El semanario El Campesino, más allá del papel que jugó en el engranaje de la Educación Fundamental Integral, adquirió importancia por sí solo, pues no solamente llegaba a quienes hacían parte de las Escuelas Radiofónicas, sino que era leído por un buen número de colombianos. Por su circulación nacional, se convirtió en uno de los medios más importantes de la institución. Según ACPO, el periódico recibió "la mejor y más extraordinaria acogida, no solo del pueblo agricultor, sino también de las clases dirigentes, que han visto en el semanario una respuesta a las más urgentes necesidades que el país tenía en ese campo." Para finales de 1960 se editaban normalmente 74.000 ejemplares, y de acuerdo con los propios estimativos, después del diario El Tiempo, era el periódico con mayor circulación en el país. ${ }^{157}$

Si bien el periódico El Campesino empezó a publicar las cartas de sus lectores desde 1958, antes de ese añoya se había creado un Departamento de Correspondencia en ACPO, que tenía como función principal responder todas las cartas recibidas. Desde que se iniciaron oficialmente las Escuelas Radiofónicas en 1949, las cartas se constituyeron en el único medio de comunicación directa entre los alumnos y los profesores de la institución. Estas se convirtieron en un medio práctico para

156. El Campesino, Bogotá, 29 de mayo de 1960.

157. El periódico El Campesino del 29 de abril de 1962 muestra en la página 16 una detallada lista de las poblaciones a donde llega el semanario acompañada del número de ejemplares enviados a cada una de ellas. Igualmente hace un resumen del número de ejemplares por departamentos. Para esta fecha El Campesino distribuye, según el registro publicado, un total de 118.042 ejemplares. 
complementar la enseñanza radial. Era la única posibilidad económica y accesible para tener una retroalimentación o una respuesta de la labor que se desarrollaba en las Escuelas Radiofónicas.

Entre 1953 y 1967, ACPO recibió y contestó un total de 521.519 cartas de campesinos. Estos escritos hacían alusión a situaciones relativas con el funcionamiento de las mismas Escuelas, ya fuera en relación con sus contenidos, con los medios utilizados o con la metodología. También se podía encontrar una variedad de misivas que estaban dirigidas a la institución, agradeciendo la labor prestada y comentando los adelantos que se habían tenido en los diferentes aprendizajes. ${ }^{158}$ María del Carmen Maldonado, en una carta escrita el 10 de junio de 1966 desde el municipio de Carmen de Carupa, en Boyacá, comentaba las mejoras que realizó: "En la casa estoy comenzando con la higiene de la vivienda y la higiene de personas", y manifestaba que desde hacía dos años tenía su radio y estaba trabajando como Auxiliar Inmediato en la escuela donde asistían vecinos y familiares. ${ }^{159}$ De otra parte, las cartas se convertían en un medio de control sobre los problemas que se presentaban en el funcionamiento de las Escuelas Radiofónicas o en las actividades de los líderes. Una de las representantes parroquiales comunicaba a ACPO la necesidad de que le enviaran unos radios para comprarlos a plazos:

Cáqueza, octubre 2 de 1966

Reverendo padre José Ramon Sabogal

Bogotá

R.P. lo saludo con todo respeto deceandole que Dios lo colme de bendiciones.

Padre le contare lo sigiente estuvi esta cemana una santa mision en lavereda y able con el padre misionero del moimiento radiofonico pero un fue posible que le quedara tiempo de acerle propaganda me dijo que esa comunidad tenia varios radios, en la caja se acavaron yo necesito unos 5 radios ojala que fueran a pasos.

158. ACPO cuenta con un archivo de las cartas enviadas por los estudiantes y de las respuestas escritas por los funcionarios de la institución. Este archivo está organizado por años, desde los inicios de ACPO. La revisión y análisis de las cartas se hizo especialmente del año de 1966, periodo al que se tuvo acceso en los archivos de Acción Cultural Popular en el municipio de Sutatenza.

159. Carta de María del Carmen Maldonado dirigida a Acción Cultural Popular el 10 de junio de 1966. 
Padre tenga la vondad de mandarme decir su las comprobaciones de las reuniones de cada mes, a donde tengo que mandarles que he mandado 2 y no se si las abran resividas.

Padre, able con momceñor del asusnto de los radios en Bogotá y dijo que es que ahel no le queda y el padre coadjutor tiene que dar clases en el colegio de varones y ninguno puede hir.

Padre le pido el favor de no pasar ninguna carta al programa de correo. Padre tenga labondad de escusarme que por no escrivirle sino que no me queda tiempo.

Padre medespido pidiendole mede su santa bendicion.

Ana Cecilia Melo T.

Reprecentante parroquial (sic)

Mediante estas cartas, ACPO conocía sobre lo que sucedía en las diferentes Escuelas Radiofónicas y comunidades parroquiales. Los mismos estudiantes se encargaban de informar sobre las necesidades, las carencias y los logros. Esto permitió que los programas de las nociones se fueran actualizando. Con la fundación del periódico El Campesino, algunas de las cartas eran publicadas y dadas a conocer por este medio, lo que permitió la socialización de los problemas del campesinado en diferentes ámbitos.

Los medios mencionados anteriormente tienen relación directa con instrumentos de comunicación; sin embargo, en los elementos de acción se contaba con los Institutos Campesinos, que se crearon para la formación de aquellos que iban a ocupar algún cargo dentro de la estructura local de las Escuelas Radiofónicas. Es decir, en estos institutos se formaban los Auxiliares Inmediatos, los Dirigentes Campesinos o los Auxiliares Parroquiales. ACPO creó en Sutatenza dos institutos para que los campesinos de todo el país recibieran actualizaciones e instrucción durante cuatro meses. Uno de los institutos era para las mujeres y el otro para los hombres.

El instituto de hombres se estableció en 1953, y con la colaboración de los párrocos se hizo una selección del primer grupo de dirigentes campesinos que permanecieron internos durante cuatro meses recibiendo formación en las cinco nociones de la Educación Fundamental y en la adquisición de competencias para la comunicación interpersonal, mediante el aprendizaje de un mayor vocabulario 
y el ejercicio del diálogo y la discusión. De la misma manera, en 1957 se abrió el instituto de mujeres, donde también se capacitó a aquellas mujeres que iban a cumplir un papel de liderazgo en las Escuelas Radiofónicas. Quizás uno de los aspectos más importantes de la experiencia de la Escuelas Radiofónicas fue incorporar a la mujer en este tipo de procesos, de los cuales tradicionalmente se hallaba relegada. A finales de los 50 y principios de la década del 60, las mujeres campesinas relacionadas con ACPO empezaron a ingresar al proyecto asumiendo nuevos roles dentro de la estructura local de la institución.

Los criterios de selección para ingresar a los Institutos Campesinos consistían en tener una edad mínima de 18 años, saber leer y escribir y pertenecer a una familia campesina, honorable, propietaria y solvente. Además, dentro de las condiciones se estableció que "tengan inteligencia suficiente y que tengan capacidad para ser dirigentes", 160 condiciones que evaluaba el cura párroco, quien era el encargado de dar el aval para ingresar al instituto. ${ }^{161}$

El fin principal de los institutos era “la formación apostólica de estos dirigentes, encaminada a la adquisición de conocimientos que les sirvan para colaborar con los señores párrocos y con sus hermanos campesinos para llevar a cabo una auténtica campaña de la revaloración de la vida rural". ${ }^{162}$ Estos institutos sacaban dos promociones de dirigentes al año. Una iba de febrero a junio, y la otra, de agosto a diciembre.

Con la formación de estos dirigentes se logró consolidar un amplio grupo humano que trabajara al lado de los campesinos y que apoyara las labores parroquiales. Su afianzamiento como dirigentes les permitió organizar mejor a las comunidades y hacer parte posteriormente de juntas veredales o juntas comunales que fueron apoyadas en las páginas del periódico El Campesino. ${ }^{163}$ Por eso algunos temas tratados con las nociones tenían que ver con la participación ciudadana, el desarrollo comunitario y el liderazgo. ${ }^{164}$ ACPO intentaba responder así a sus principios, pues en ellos planteaba que las actividades de Acción Cultural Popular favorecían "la creación de un movimiento desarrollado por unos militantes

160. El Campesino, Bogotá, 28 de febrero de 1980, Bogotá, p. 12.

161. Informe a la Venerable Conferencia Episcopal, 1961 a 1964, Bogotá, p. 44

162. El Campesino, Bogotá, 28 de febrero de 1980, Bogotá, p.12

163. El Campesino, Bogotá, 5 de noviembre de 1961, Bogotá, p. 8

164. Un plegable promocional de los Institutos Campesinos de Sutatenza indicaba las clases, los temas y la metodología utilizada en los institutos para la formación de líderes. Este plegable se encontró en los archivos de ACPO en Sutatenza. 
que encarnen una doctrina de vida en una acción solidaria organizada". ${ }^{165}$ Y así lo venían haciendo al capacitar a los campesinos para que lograran ocupar un lugar privilegiado dentro de su comunidad como dirigentes y organizadores de diferentes grupos sociales.

Los medios de acción mencionados se consolidaron como los más importantes dentro de la formación del campesinado, no obstante, después de 1960 se inaugura la prensadora de discos de ACPO que se empleaba para grabar canciones folclóricas y de estilo campesino, música popular, pequeños poemas y mensajes de tipo cultural. ${ }^{166}$ Con la producción magnetofónica, ACPO buscaba que las diferentes emisoras de Radio Sutatenza pudieran pasar las clases en diferentes momentos y pudieran divulgar algunos trabajos musicales que se grababan con el ánimo de promocionar la música popular. La institución tenía en Bogotá los equipos necesarios para la prensa de discos que le permitía realizar las grabaciones. Hasta el año de 1967, el número de discos prensados por ACPO llegó a 16.582, distribuidos en la diferentes Radio Sutatenza del país.

Además, se crean las Bibliotecas del Campesino, medios que aportan significativamente al proceso de lecto-escritura de los estudiantes. Las bibliotecas surgieron como un complemento a las clases radiales y a las cartillas. El material impreso en la Editorial Andes, una de las empresas de ACPO, ampliaba los conceptos y conducía las ideas prácticas para su posterior aplicación. La colección contó con 100 temas, impresos en pequeños libros de bolsillo que fueron vendidos mediante un sistema de canje desarrollado con los tenderos de las veredas, y denominado 'Un libro por un huevo'. ${ }^{167}$ Los libros de la biblioteca trataban temas que tenían que ver con literatura, religión, arte, técnicas para el trabajo, el deporte y el entretenimiento. ${ }^{168}$

El informe de ACPO a la conferencia Episcopal entregado en 1964 registró una impresión de 100.000 libros correspondientes a 10 colecciones, cada una con 10 libros, para un total de 100 títulos. Entre los libros editados hasta ese año, estaban: La buena nueva, La madre y el niño, Qué bueno ser colombiano, La vaca del campesino; y libros que reforzaban los conceptos relacionados con la higiene y la salud como el de Primeros Auxilios; la organización de las comunidades como Cooperativa de

165. HOUTART, Francisco y PÉREZ, Gustavo. Acción Cultural Popular. Sus principios y medios de acción, op cit., p. $40 B$.

166. MARTíNEZ, Emiro. Métodos de periodismo rural en el semanario El Campesino, Editorial Andes, Bogotá, 1978, p. 28.

167. Revista Presencia, octubre de 1960, No. 99, p.44.

168. El Campesino, Bogotá, 14 de enero de 1968. 
ahorro y crédito; o la historia y el civismo en el texto El precursor. Buena parte de estos libros tenían relación con las nociones de la Educación Fundamental Integral y buscaban reforzar los conocimientos impartidos en las Escuelas Radiofónicas.

Los elementos de acción, en general, cumplieron un papel de apoyo a la labor desarrollada desde la radio con las Escuelas Radiofónicas. En medio de las nociones básicas que permitían una formación en áreas consideradas fundamentales por ACPO, se realizaban las Campañas, que eran acciones prácticas pero sustentadas en los principios teóricos que regían la Educación Fundamental Integral. En este sentido, las campañas se concibieron como una adopción de innovaciones resultante de la acción de conocer y de saber. La idea principal a la hora de implementarlas consistió en la necesidad de que el campesino incorporara nuevos elementos a su realidad, se apropiara de ellos y los realizara en su entorno, encontrándoles sentido tanto para su vida como para su comunidad. Por eso se establecieron campañas orientadas en varios frentes.

La campaña Suelo perseguía el desarrollo de las prácticas para la defensa del suelo y de la naturaleza, y buscaba que el campesino aprendiera cómo conservar la tierra. Otra campaña fue la de Vivienda, que pretendía que los campesinos mejoraran sus viviendas y desarrollaran prácticas en torno a ella que tenían que ver con la higiene, el aseo, la distribución de espacios, la implementación de jardines y huertas. Otro aspecto que trabajó ACPO en las campañas estuvo relacionado con la Nutrición, para que los campesinos tuvieran un adecuado y balanceado consumo de alimentos; igualmente la Recreación, que estuvo orientada hacia los deportes, el teatro, la literatura y la música, entre otros; y la Procreación responsable, que fue una campaña que implementó ACPO con el ánimo de que los campesinos tuvieran una orientación dirigida hacia el cuidado de los hijos y el manejo responsable de las relaciones sexuales. ${ }^{169}$ Las áreas que cubrían estas campañas eran aquellas que, de una u otra manera, se trabajaban a partir de las clases que se daban en las Escuelas Radiofónicas. Las campañas eran instrumentos de refuerzo de los aprendizajes obtenidos previamente por la mayoría de los estudiantes.

Estas campañas se realizaron mediante una coordinación sistemática por parte de todos los mensajes difundidos en los diferentes medios, buscando el sentido de la acción misma. En esencia fue la aplicación práctica de un conocimiento, pues se intentaba que los campesinos desarrollaran las acciones recomendadas en sus

169. BERNAL, Hernando. "Radio educativa para el desarrollo rural: El precursor Radio Sutatenza y Acción Cultural Popular, su influencia en la región", en Radio y democracia en América Latina. IPAL - Instituto para América Latina, Lima, 1989, p. 106. 
entornos. El campesino, en la Educación Fundamental Integral, transitaba así de las palabras a los conceptos, de estos a las ideas, y de las ideas a la praxis por medio de las campañas.

Las campañas fueron el instrumento donde se hizo uso sistemático de los medios de acción. Estas campañas se programaban durante varias semanas en las Escuelas Radiofónicas, especialmente los sábados, ${ }^{170}$ y entre tanto en el periódico El Campesino aparecía semanalmente una página dedicada a temas relacionados. ${ }^{171}$ Igualmente, los líderes campesinos divulgaban y promocionaban el tema en los diferentes pueblos.

Habitualmente los medios de acción fueron utilizados en todo el sistema de la Educación Fundamental Integral, y cumplieron papeles de refuerzo de los mensajes de acuerdo con los fines y objetivos propuestos, ya fuera en los cursos, en las cartillas o en las diferentes campañas que se realizaron. Para la institución, las Escuelas Radiofónicas fueron el eje articulador del accionar de cada uno de los medios. Aunque las clases se daban en la radio, perdían sentido sin la existencia de los grupos de estudiantes que conformaban las Escuelas Radiofónicas. La constitución de los grupos familiares o de vecinos en torno a las clases radiales era considerada vital para que los campesinos comprendieran las posibilidades de recibir una educación que los enriqueciera individualmente y que les permitiera forjar proyectos comunes. De acuerdo con el papel que tuvieron las Escuelas Radiofónicas dentro del todo el sistema, fueron consideradas como una célula vital del movimiento de ACPO.

Los medios para los cuales trabaja Acción Cultural Popular para la dignificación del pueblo son varios... Pero la Escuela Radiofónica es la célula vital del movimiento, la Escuela Radiofónica vive en el lugar del campesino, donde transcurre su vida, desarrolla su actividad y ocurren sus preocupaciones, a donde acuden familiares y vecinos. El centro de recepción organizado, la acción del Auxiliar Inmediato, la utilización de los materiales gráficos, la llegada del semanario, la acción permanente de la radio, constituyen el centro, la célula, el origen de una acción que busca la “EDUCACIÓN INTEGRAL CRISTIANA DEL PUEBLO”, con sistemas que abarquen su cultura básica y la preparación para la vida social y económica...

170. De acuerdo con las programaciones publicadas en El Campesino, la transmisión radial de las campañas se realizaba los días sábados.

171. Para observar un ejemplo de las campañas realizadas por ACPO, relacionadas con el tema de la vivienda, se puedo revisar la edición del periódico El Campesino del 5 de julio de 1959. 
El alumno de la escuela radiofónica se educa para sí y para los demás. El Auxiliar Inmediato actúa en beneficio propio, de sus alumnos y de la comunidad. Todos buscan un mismo fin y se mueven por los mismos ideales.

Son parte de una organización familiar len la misma Escuela Radiofónica), veredal, parroquial, diocesana y nacional. TODO ESTO SIGNIFICA EN ACCIÓN CULTURAL POPULAR, LA CÉLULA VITAL DE TODO UN MOVIMIENTO. ${ }^{172}$

En general, el sistema de ACPO poseía tres grandes componentes indispensables para su accionar. Inicialmente una serie de conceptos que constituyeron la ideología de Acción Cultural Popular desde que inició la Emisora Sutatenza hasta el trabajo de reflexión realizado por Houtart y Pérez a finales de los años cincuenta y a principio de los 60. En ese momento se dejó explícita la ideología de la institución en relación con el desarrollo, especialmente de las comunidades campesinas. De otra parte, una serie de procesos que se transformaron en una metodología de la acción educativa y la intervención social, de acuerdo con un orden y funcionamiento de los propios procesos. Y, por último, la puesta en marcha de unos medios o instrumentos de comunicación y de producción que se constituyeron en herramientas que aportaban en el cumplimiento de los objetivos sociales propuestos, pero también a la consecución de recursos externos para el mantenimiento de la institución.

Estos tres componentes que permitieron el funcionamiento de ACPO, durante varias décadas, compartieron un lugar común: el origen y desarrollo a partir de la praxis. Antes que las reflexiones teóricas, la misma práctica fue la que guió el curso de acción de ACPO. Por eso no es extraño que cuando Houtart y Pérez escribieron Los principios y medios de acción de ACPO, un buen número de los medios utilizados ya estaban establecidos con anterioridad. Realmente, el aporte en este sentido fue que al proceso nacido de la práctica se le dio una sustentación teórica, que le permitió a la institución fundamentar y consolidar su accionar durante cuatro décadas más. Se pasó de la etapa de experimentación a la etapa de acción intensiva. ${ }^{173}$

172 El Campesino, Bogotá, 14 de abril de 1963, Bogotá, p. 3.

173 El Libro Azul, hace mención de estas dos etapas en la historia de ACPO. Antes y después de la definición de los principios y medios de acción de la institución. 


\section{ACPO y su apoyo a la reforma agraria}

La carencia de tierras por parte del campesinado colombiano fue una preocupación de Acción Cultural Popular que se hizo evidente incluso antes de que el gobierno de Alberto Lleras Camargo aprobara la Ley de reforma agraria en 1961. Desde años antes, en efecto, ACPO presionó a través de sus diferentes medios, especialmente del periódico El Campesino, para que se tuviera en cuenta el tema de la injusticia de la propiedad agraria y para que se llevaran a cabo algunos cambios que permitieran el acceso de los campesinos a la tierra productiva.

El semanario, desde 1958, hacía alusión en su portada a este tema mediante una frase que rezaba "Los hombres sin tierra tienen derecho a la tierra sin hombres", ${ }^{174}$ recordando la cantidad de extensos terrenos no utilizados para el cultivo y la cantidad de campesinos que carecían de tierras o tenían pequeños minifundios que no lograban producir lo necesario para acceder a los recursos que les permitiera cubrir sus necesidades básicas.

Orlando Fals Borda en su trabajo 'El Hombre y la Tierra en Boyacá', planteaba cambios institucionales para poder realizar una reforma agraria y una organización del mercado de trabajo, y la necesidad de que el país empezara a dotarse de un sistema de transporte que permitiera la movilidad tanto de los productos como de los campesinos. Describía entonces cómo hasta ese momento el transporte de los productos agrícolas "se efectuaba casi todo a espalda o sobre la cabeza de los seres humanos, en carretas de dos ruedas tiradas por bueyes o en pequeños vehículos de cuatro ruedas llamados zorras". ${ }^{175}$

Si bien el problema del acceso a la tierra por parte de amplios sectores campesinos se trató desde gobiernos anteriores, especialmente desde el primer gobierno de la república liberal, a cargo de Alfonso López Pumarejo, no se pudo consolidar una política clara en este sentido durante los siguientes años. El triunfo de la revolución cubana y la violencia existente en el país fueron las causas que llevaron a que la preocupación por los problemas sociales, especialmente del campesinado, cobrara importancia.

La Iglesia, a finales de los años de 1950 y principios de 1960, empezó a hacer “llamados de atención sobre las condiciones de los sectores menos desfavorecidos,

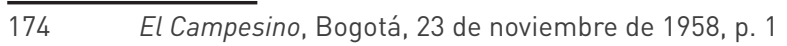

175 FALS Borda, Orlando, El Hombre y la Tierra... pp.191 y 192 
en la creación de comisiones episcopales dedicadas al estudio de asuntos sociales, así como el interés por cuestiones que hasta entonces no habían merecido mayor cuidado, como el problema agrario". ${ }^{176}$ El periódico El Campesino constantemente hizo eco de las palabras de la Iglesia en este sentido, donde no solo denunciaba la penetración del comunismo en el país y su posible influencia en el campesinado, sino que también denunciaba las condiciones en que se encontraban los campesinos por la falta de recursos para cultivar, por la injusta remuneración, por el creciente desempleo o por la falta de tierra. De nuevo el problema de los campesinos empezaba a tomar relevancia y "para ese entonces, la lucha por la tierra y por las condiciones del trabajador rural han vuelto a cobrar gran importancia, por lo que el gobierno, a finales de los sesenta, incluye en su agenda ese delicado problema". ${ }^{177}$

Aunque la política agraria del gobierno no estuvo condicionada a la opinión de Acción Cultural Popular, sí influyó significativamente porque el seguimiento que se realizó en el periódico fue constante. Precisamente desde 1958, año en que se fundó el periódico El Campesino, el tema de la reforma agraria estaba discutiéndose en el escenario político nacional. En ese mismo año, la Conferencia Episcopal había señalado que era el momento para que se realizara una reforma agraria y social que permitiera una riqueza productiva más equitativa. ${ }^{178}$

Ricardo Arias hace mención de las acciones tomadas por la Iglesia sobre el tema agrario en los años siguientes. Destaca cómo en 1959 se realizó el primer Congreso Nacional Católico de la vida rural, donde el clero fijó su posición frente a la problemática campesina, y cómo en 1960 los obispos declararon que la reforma agraria era una de las necesidades más apremiantes del país. Sectores como el de los jesuitas, en la Revista Javeriana criticaron la tenencia de tierras sin una utilización económica plena y destacaron la conveniencia de expropiar las tierras que estuvieran siendo desaprovechadas. ${ }^{179}$

Mientras la Iglesia hacía el planteamiento del tema agrario como una prioridad para el país y este se debatía en los diferentes escenarios, entre ellos los medios de comunicación, en 1959 ya se empezaban a ver algunas respuestas a la situación del campesinado y se evidenciaba en la declaración del gobierno ante la Sociedad

\footnotetext{
176. ARIAS, Ricardo. Episcopado Colombiano: Intransigencia y laicidad (1850 - 2000), Bogotá, Ediciones Uniandes, 2003 p. 195.

177. Ibid.

178. Ibid.

179. Ibid.
} 
Colombiana de Agricultura, donde manifestaba unos avances en el tema de política agraria. Allí se propuso fomentar la industria agropecuaria con un programa de utilización de tierras sin explotar, de entrega de tierras a los campesinos, de facilitación de asistencia técnica, de crédito a largo plazo con intereses reducidos, con el fin de poner en marcha una maquinaria adecuada para impulsar la agricultura y la ganadería. Para ACPO, el programa planteado por el gobierno respondía a las necesidades nacionales y hacía énfasis en lo que ya se venía reclamando desde hacía mucho tiempo.

El programa del gobierno expuesto a la Sociedad Colombiana de Agricultura era la primera iniciativa que se presentaba al país en el marco de la reforma agraria aprobada posteriormente. ACPO valoró, en su medio de comunicación impreso, dicha declaración, puesto que consideraba que la situación actual del campesinado no le permitía disponer de los recursos para "hacerles frente a las múltiples contingencias que lo rodean. Si es propietario de una pequeña parcela, cansada por el intenso laboreo, no encuentra facilidades para abonarla, ni crédito para adquirir herramientas, ni semillas, ni asistencia técnica, ni consejos oportunos para defender sus cultivos de plagas y enfermedades". 180 Pero además, exhortó a la dirigencia del país para que apoyara el programa del gobierno en este sentido, pues no respondía a los intereses políticos de un sector determinado, sino que reflejaba una realidad nacional que era inquietante por la difícil situación de la economía. Para ACPO era importante evitar que por las rencillas, los intereses o las posiciones políticas, se frustrara la posibilidad de que el campesinado accediera a beneficios relacionados con la explotación de la tierra, la asistencia técnica por parte del Estado y la posibilidad de adquirir créditos con facilidades. En su opinión, esas posiciones habían obstinadamente "detenido el progreso del país". ${ }^{181}$

Ante la eventual posibilidad de que se abriera un camino hacia la reforma agraria, Acción Cultural Popular celebró las nuevas decisiones sobre política agraria y se mantuvo a la espera de los resultados que las medidas produjeran hacia el futuro.

Cuando se iniciaron las discusiones de la reforma agraria, ACPO publicó en El Campesino las bases que consideraba como necesarias para una adecuada reforma. Estas eran que fuera económicamente sana, moralmente justa, socialmente democrática y prácticamente moderna. ${ }^{182}$ La coherencia entre lo afirmado por el

180. El Campesino, Bogotá, 1 de febrero de 1959, p. 3

181. El Campesino, Bogotá, 1 de febrero de 1959, p. 3

182. El Campesino, Bogotá, 24 de julio de 1960. p. 1 
semanario y por el episcopado era evidente, pues el segundo reconocía que "la reforma agraria es inevitable, pero agrega que la respuesta a las necesidades del campesino no puede ser solo material, pues en el transfondo de esta crisis aparece el problema moral". 183

El semanario en la edición del 24 de julio de 1960 imprimió una encuesta sobre la reforma agraria para que la contestaran los lectores. Esta constaba de cinco preguntas que tenían que ver con la situación económica actual del pueblo agricultor y se pidió la opinión del campesinado para saber qué consideraban ellos como conveniente para mejorar su situación. Además, se indagó, por medio de selección múltiple, sobre los aspectos donde se esperaban soluciones y mejoramiento; entre las respuestas estaban construir más escuelas, más carreteras, más caminos, más hospitales, abrir más fuentes de trabajo y destinar más préstamos en dinero. También se le preguntó al campesinado por la institución o instancia que consideraban podía hacer algo por ellos. Entre las respuestas para marcar estaban en este orden: el gobierno, la Iglesia, Radio Sutatenza, el periódico El Campesino, el comunismo, el protestantismo, las juntas veredales, los partidos políticos, los sindicatos, los patronos, los hacendados, la masonería y la Caja Agraria.

La idea de la encuesta era dar a conocer las respuestas al gobierno y al Congreso Nacional, e iniciar una campaña a favor de la reforma agraria. ACPO, por medio de la encuesta, propiciaba una participación del campesinado para que se diera la reforma, pero también privilegiaba algunas acciones más que otras. Las posibles respuestas, especialmente las que tenían que ver con las instituciones, mostraban al periódico El Campesino, a Radio Sutatenza o a la misma Iglesia como unas organizaciones que podían sustituir, en algunos aspectos, las actividades que ya se había empezado a discutir en el país.

Durante todo el año de 1960, las páginas de El Campesino y las instalaciones de Acción Cultural Popular fueron escenario de las discusiones y reuniones referentes al tema de la reforma agraria. El 28 agosto de ese año, El Campesino publicó la noticia sobre el envío de un prospecto de reformas de la Federación Agraria Nacional (FANAL ${ }^{184}$ ) a las Cámaras Legislativas, con el ánimo de que el Congreso Nacional las estudiara y las adoptara dentro de las discusiones sobre el tema de la reforma y como una solución a los problemas sociales y económicos del sector campesino ${ }^{185}$.

183. ARIAS, Ricardo. Episcopado Colombiano: Intransigencia..., op cit., p. 196.

184. Fanal fue una federación fundada y apoyada por la Iglesia Católica en 1946, con la intención de realizar acciones que aportaran a los problemas del país, especialmente los relacionados con el sector agrario.

185. El Campesino, Bogotá, 28 de agosto de 1960, p. 1. 
Del mismo modo, el auditorio de Acción Cultural Popular sirvió para que se dieran a conocer y se discutieran informaciones relacionadas con el tema de la reforma agraria. Los estudios realizados para tal fin por un comité coordinado y dirigido por Carlos Lleras Restrepo, a petición del presidente Alberto Lleras Camargo, fueron dados a conocer el 24 de octubre ante 500 personas en el auditorio mencionado. La realización de este evento en ese escenario dejó ver la importancia de ACPO en el marco de las discusiones de la reforma, y lo mostraba como una institución que representaba al campesinado, como un vocero de los intereses del sector agrario del país. Es claro que la posición de ACPO era privilegiada, pues era identificado como un actor principal en las discusiones sobre el tema, lo que le permitía intervenir, explicar y presionar para que los aspectos que consideraba importantes se incluyeran en los proyectos. ${ }^{186}$

El trabajo realizado por Carlos Lleras Restrepo dejó ver una estructura arcaica del factor primario de la producción y un atraso en el régimen de la propiedad rural que no había respondido a las necesidades y exigencias de la demanda de los bienes de consumo. Una de las preocupaciones del comité era la creciente aparición de sectores de personas "desocupadas, analfabetas, ambulatorias y exasperadas que constituyen el caldo de cultivo de los extremismos", ${ }^{187}$ por eso la necesidad de buscar soluciones de equilibrio, como las llamó Lleras Restrepo, para el buen funcionamiento de la economía, pero también para generar una producción que respondiera a las necesidades de los pueblos. La reforma agraria se convertía en la opción para la reestructuración del "sistema que permita modernizar la vida económica colombiana y aliviar las tensiones sociales acumuladas como producto del desajuste actual". ${ }^{188}$

El discurso de Lleras Restrepo mostró una posición común con la que expresó continuamente ACPO en el periódico El Campesino, y que consistía en que la reforma agraria no solo significa la tenencia de la tierra y la distribución de la misma, sino que estas acciones implicaban tomar medidas en relación con la educación, la salubridad y las comunicaciones, temas que venían trabajando las Escuelas Radiofónicas en sus clases radiales.

186. Carlos Lleras Restrepo en su explicación sobre el proyecto de reforma agraria en la revista Semana del 31 de octubre de 1960 confirmó como organismos representativos de los trabajadores rurales a la Iglesia, al Estado y al Ejército, y los denominó "factores reales de poder", por estar en contacto asiduo con los casi 7 millones de trabajadores rurales que sufren una serie de problemas.

187. Semana, 31 de octubre de 1960, p. 22

188. Ibid. 
De acuerdo con los enunciados expuestos en el auditorio de Acción Cultural Popular, el proyecto establecía un organismo que administraría el plan y que lo pondría en marcha. Los objetivos que tenía previstos eran:

a) Modificar las estructuras del sector para extirpar las concentraciones excesivas (latifundios) y evitar el fraccionamiento (minifundio). (sic)

b) Dotar de tierras adecuadas a quienes no las posean y se dediquen a cultivarlas;

c) Poner bajo cultivo las extensiones que hoy no lo estén y que sean susceptibles de explotación de acuerdo con los programas económicos globales;

d) Acrecer el volumen de la producción agropecuaria y aumentar los índices de la productividad (rendimiento hombre-hora);

e) Hacer fácil el acceso a la propiedad de la tierra de los pequeños arrendatarios, parceleros o aparceros (incorporan trabajo y dividen utilidades), y

f) Preservar los cursos naturales y asegurar su empleo adecuado. ${ }^{189}$

El organismo encargado para llevar a cabo ese programa fue el Instituto de la Reforma Agraria - INCORA- creado en el año de 1963, que, además de los objetivos enunciados anteriormente tenía otras funciones específicas como:

- Administrar las tierras baldías de propiedad de la Nación.

- Administrar el Fondo Nacional Agrario (Financiación).

- Orientar el desarrollo económico del sector en cuanto a tenencia, uso de las tierras, distribución de las aguas, recuperación de superficies inundables y lucha contra erosión.

- Fomentar el saneamiento de la titulación y cooperar en la formación de los catastros.

- Promover la construcción de vías y ejecutarlas directamente para los fines provistos.

- Promover y ejecutar las obras de reforestación, drenaje, regadíos, colonizaciones, parcelaciones o concentraciones donde sea necesario cambiar la estructura de la propiedad.190 
Sibien los enunciados del proyecto inicial de la reforma agrariay los objetivos propios del INCORA no daban claridad frente a los aspectos relacionados con la formación del campesinado, Lleras Restrepo sí había hecho mención de la necesidad de actuar con el campesinado analfabeta. Pero además ACPO, en las páginas del semanario El Campesino, fortaleció esa idea con la continua publicación de declaraciones que reforzaron la imperiosa necesidad de educar a la población campesina para que la reforma funcionara. Entre otras, fueron publicadas las palabras de Eduardo Carbonell, gobernador del departamento del Atlántico, quien manifestó estar de acuerdo con la campaña de ACPO en el sentido de que el gobierno debería "incrementar la educación entre las masas campesinas, porque de nada va a servir la reforma agraria si esta no llega a elementos que por su educación puedan hacer buen uso de ellas". ${ }^{191}$ En el marco del debate y discusiones sobre el tema de la reforma, El Campesino titulaba "Sufrimos la tragedia de ignorarlo todo y es tanta nuestra pobreza y nuestra miseria que aunque nos repartieran tierras, no tendríamos cómo trabajarlas ni cómo sostenerlas". 192

De esta manera, ACPO no solo se proyectaba como una institución que velaba por que los campesinos recibieran unas tierras para cultivar los diferentes productos agrícolas, sino también como un organismo dedicado a la educación. Así buscaba que la formación educativa del campesinado se incorporara en el proyecto de una reforma agraria integral, como la denominaría ACPO, haciendo uso del término utilizado dentro de su modelo de Educación Fundamental Integral. Es decir, la reforma agraria no solo debía tocar el tema de tierras y la producción, sino que debía incluir todos los aspectos que estuvieran relacionados con el bienestar del campesinado.

El Campesino, finalizando 1960, hizo circular en sus páginas una segunda encuesta sobre la reforma agraria, donde indagaba sobre lo que se esperaba del plan de tierras, de la forma en que consideraban se podía aplicar la distribución, las clases de tierras que debían ser tenidas en cuenta para incorporarlas a la producción, y las zonas geográficas donde se debía llevar a cabo ese plan de tierras. A partir de las primeras respuestas recibidas, El Campesino publicó artículos desarrollando las propuestas de los lectores. Precisamente en uno de ellos hacía mención de que, debido a que los campesinos cultivarían otro tipo de frutos diferentes a los tradicionales, la repartición de tierras diversificaría la producción. Acompañada de dicha información, el texto mencionaba la necesidad de educar al campesinado en el cultivo de nuevos productos. ${ }^{193}$

191. El Campesino, Bogotá, 6 de noviembre de 1960.

192. El Campesino, Bogotá, 28 de agosto de 1960.

193. El Campesino, Bogotá, 11 de diciembre de 1960 
El discurso de reforma agraria unido a la educación llegó a incidir tanto en la opinión pública y en el gobierno que hasta el mismo ministro de Agricultura, Otto Morales Benítez, se refirió a la necesidad de darle un fuerte impulso a la educación rural popular para no terminar haciendo una reforma a medias. ${ }^{194}$ Estas declaraciones fueron dadas en los primeros días de 1961, año en que se aprobó finalmente la Reforma Social Agraria por parte del Congreso Nacional, mediante la Ley No 135.

El artículo quinto de dicha ley, que rezaba: “Elevar el nivel de vida de la población campesina, como consecuencia de las medidas ya indicadas y también por la coordinación y fomento de los servicios relacionados con la asistencia técnica, el crédito agrícola, la vivienda, la organización de los mercados, la salud y la seguridad social, el almacenamiento y conservación de los productos y el fomento de las cooperativas", contenía varios aspectos de los impulsados por Acción Cultural Popular en el sentido de que la reforma debería ser integral. La Ley incluía la formación mediante la asistencia técnica, pero también la atención al campesinado en materias como la salud y la asociación.

Sin embargo, para poder tener un protagonismo real y para que se llevaran a cabo proyectos en las áreas mencionadas, era necesario que se organizaran los Comités Municipales de Reforma Agraria creados mediante el decreto 3177 de diciembre de 1961. Por eso, luego de aprobada la reforma, ACPO empezó a publicar artículos en el semanario invitando y exhortando a los campesinos para que presionaran para la organización de dichos comités y, por supuesto, para que hicieran parte de los mismos.

Consideramos indispensable hacer un llamamiento muy especial a todos nuestros lectores, en particular a los dirigentes campesinos y a los miembros de las Juntas Veredales, para que procedan sin dilaciones a exigir la pronta constitución en cada uno de los municipios de los Comités Municipales de la Reforma Agraria...

Como podrán haberlo visto en el decreto publicado por nosotros en la edición anterior, en cada municipio funcionará un Comité de la Reforma Agraria, integrado por el Cura Párroco, el Agente de la Caja de Crédito Agrario, si existiere; dos representantes del Concejo Municipal, que pueden ser concejales o no, de filiación política distinta, 
elegidos directamente por dichas corporaciones; y uno designado por las Juntas Locales de Acción Comunal. Los tres últimos tendrán un período de dos años contados a partir del primero de este mismo año de 1962, y dos suplentes numéricos que, en su orden, los reemplacen en caso de falta. Los dos primeros podrán designar delegados suyos que los reemplacen cuando no pudieran concurrir ${ }^{195}$.

Estos Comités cobraban importancia en las diferentes regiones, pues aunque eran órganos consultivos, tenían como objetivo el estudio de los problemas de la tenencia de tierras en la zona y los conflictos que se daban por tal causa, pero así mismo planteaban las posibles soluciones a tener en cuenta entre las que estaban la colonización, la parcelación o las concentraciones parcelarias. Era claro que la participación del cura párroco, sumado a los representantes de los concejales y al representante de la Junta de Acción Comunal, daba un amplio margen de maniobra y amplias posibilidades de incidir en las decisiones por parte de ACPO, si el trabajo se llevaba a cabo en lugares donde tenía presencia la organización.

Desde la aprobación de la Ley en diciembre 13 de 1961 hasta mayo de 1962, El Campesino en sus páginas mantuvo la atención sobre el tema para que se llevaran a cabo las acciones necesarias y para que la ley de reforma agraria empezara a funcionar. Ante la lentitud de las acciones, el semanario empezó a publicar en su primera página un aviso que peguntaba “¿Qué hay de la Reforma Social Agraria?”, para de esta manera presionar a la opinión pública para que pidiera una respuesta rápida. El interrogante iba acompañado de una frase distinta cada vez. En la edición 200 del semanario fue: “Esta es la pregunta que está interpretando la expectativa nacional de los agricultores ante la tan esperada aplicación de la Ley de reforma agraria"; ${ }^{196}$ en la siguiente edición, la pregunta estaba acompañada de la frase: “En todo el país existe gran expectativa", pero también incluía dos interrogantes más ¿cuándo?, y ¿dónde? ${ }^{197}$ En la misma página, ACPO seguía difundiendo su idea de que la reforma debía ir acompañada de la formación educativa. Afirmaba que: "La tierra sin educación no vale". 198 La campaña realizada por el periódico fue seguida de cartas de los lectores donde reclamaban acciones concretas en torno a la reforma. Una de ellas decía:

195. El Campesino, Bogotá, 21 de enero de 1962.

196. El Campesino, Bogotá, 13 de mayo de 1962

197. El Campesino, Bogotá, 20 de mayo de 1962

198. El Campesino, Bogotá, 20 de mayo de 1962 
Qué pasa con la Reforma Agraria? No sé cómo han transcurrido ya siete meses de su aprobación y sanción y en este Departamento, [Valle] ni siquiera suena y menos truena. Qué pasa? Este Departamento no es de Colombia? 0 aquí no hay pobres? 0 no somos humanos? Yo solicito al señor Director del Incora que se sirva mover los resortes en el Comité o Instituto seccional o como quiera que se llame, que fue organizado en Cali. Se sabe que fue organizado pero no pasó de allí. Ojalá que se den cuenta de que los montañeros de Colombia estamos despertando de ese sueño campesino y sabemos que nuestra patria nos tiene un porvenir reservado. Pero, qué es lo que pasa? Presido una junta veredal y todos sus afiliados son demasiado pobres. Y esperan que la Reforma Agraria se efectúe cuanto antes. Estoy dispuesto a reclamar a diario... ${ }^{199}$ (sic)

La intención de ACPO fue mantener la atención de los campesinos en torno al tema de la reforma agraria y ejercer presión para que la Ley se ejecutara. A pesar de las pocas acciones concretas, ACPO mantuvo un discurso en relación con el tipo de reforma agraria que debía llevarse a cabo dentro de los principios generales de la Ley, por ello publicó también una columna semanal denominada 'reforma agraria integral', donde daba indicaciones sobre la forma en que debían entregarse los créditos a los campesinos y cómo ellos debían estar acompañados de adecuadas políticas en materia económica que llevaran a mejorar los ingresos de los beneficiarios y su poder de compra. ${ }^{200}$ Igualmente, hizo énfasis en la necesidad de que el país fuera de propietarios y no de servidumbre. Su argumento fue que el progreso de la sociedad no podía estar basado en esa servidumbre, puesto que el desarrollo agrario significaría transformaciones de la agricultura del momento y el sobrante de mano de obra que debía ser destinado a la producción de otros bienes. ${ }^{201}$

De esta manera, edición tras edición, se hicieron reflexiones en varias áreas relacionadas con la reforma, para incidir a través de los Comités de Reforma Agraria tanto en las políticas locales como en las nacionales. Esta dinámica se mantuvo desde los primeros años de la aprobación de la reforma agraria, hasta el año de 1968, cuando se empezaron a implementar los proyectos regionales, como el de Nariño. Allí se inició un proceso de titulación de tierras, construcción de vías y vivienda, otorgamiento de crédito y asistencia técnica. Además, se constituyó la Cooperativa Agropecuaria de Nariño para el almacenamiento de

199. El Campesino, Bogotá, 1 de julio de 1962

200. El Campesino, Bogotá, 11 de noviembre de 1962, p. 3

201. El Campesino, Bogotá, 18 de noviembre de 1962, p. 6 
los productos del campesinado de la región. Este proyecto fue destacado en las páginas de El Campesino, por tener los principios básicos de la reforma, pero también por poseer los elementos esenciales que había planteado para que fuera una reforma integral. ${ }^{202}$

La creación de nuevas instituciones como el INCORA, la Caja de Crédito Agrario y el ICA, entre otros, llevó a un replanteamiento de las acciones de ACPO, pues estos prestaban servicios directos de capacitación y extensión agrícola, de organización comunitaria y de promoción de apoyo a la salud y al mejoramiento de la vivienda campesina. Es decir, ACPO perdía terreno frente a estas nuevas instituciones. Como había apoyado la reforma agraria establecida por la Ley $135 \mathrm{de}$ 1961, se empezó un ejercicio de colaboración y apoyo mutuo entre las instituciones y ACPO. Por esta razón, algunos programas de Radio Sutatenza y algunas páginas de El Campesino se utilizaron para informar y difundir materiales escritos o instrucciones de dichas organizaciones. El INCORA, por ejemplo, constantemente hacía anuncios en el semanario y aclaraciones como la publicada bajo el título de “INCORA aclara programa en Risaralda, a los cafeteros", ${ }^{203}$ o la Caja de Crédito Agrario que promocionaba los créditos que ofrecía, utilizando avisos publicitarios donde invitaba a los campesinos a utilizar los servicios con el mensaje de "Haga uso de su crédito. Nosotros le ayudamos a financiar sus necesidades a corto, mediano o largo plazo, con prenda agraria o garantía personal, con garantía hipotecaria... ". 204 Los anuncios en el periódico y en la radio contribuían a dar la impresión de una colaboración activa en la práctica, sin embargo, este concurso se mantuvo en límites estrechos. ${ }^{205}$ La cooperación generalmente se mantuvo en los servicios que prestaban algunas instituciones del Estado y que podían ser aprovechadas por ACPO para cumplir con sus fines. Un ejemplo de esto se vio en la financiación que recibieron los campesinos para acceder a los radios transistores. En esa ocasión, El Campesino publicó el artículo titulado "Circular de la Caja Agraria sobre Crédito Campesino", donde explicaba las decisiones tomadas por las directivas de la institución financiera en el sentido mencionado:

El Gerente General de la Caja Agraria, doctor José Elías del Hierro, ha enviado a todos los gerentes de suscursales, subgerentes de Provisión Agrícola y directores de agencia una circular reglamentaria

202. El Campesino, Bogotá, 11 de agosto de 1968, p. 4

203. El Campesino, Bogotá, 20 de octubre de 1968, p. 3

204. El Campesino, Bogotá, 21 de junio de 1959.

205. MUSTO, Stefan. Los medios de comunicación al servicio del desarrollo rural, Bogotá, Editorial Andes, 1971 p. 138 
en la cual les informa que las directivas de esta entidad accedieron a la solicitud de Acción Cultural Popular para que la Caja Agraria distribuya por intermedio de sus almacenes de Provisión Agrícola, los radiorreceptores transistorizados para la sintonía de las emisiones de Acción Cultural Popular. Dicha circular señala las cinscunstancias y condiciones en que se hará este servicio de venta. ${ }^{206}$

La sustitución de las labores desarrolladas por ACPO a partir de la creación de otros institutos o dependencias manejados por el Estado y con presupuesto propio, ocasionó que los recursos de Acción Cultural Popular se redujeran significativamente y la preocupación de la institución se concentrara en la búsqueda de nuevos recursos. Por esta razón, la atención frente al tema de la reforma agraria en los años siguientes disminuyó, pero además ya se vislumbraba el fracaso de la reforma y cómo una evidencia de eso se declaraba en uno de los documentos de trabajo de ACPO, titulado "Diálogo con líderes", que el país no podía seguir manteniendo indefinidamente "jueguitos democráticos como el de la reforma agraria actual, encaminada hoy solamente a gastar millones de millones de pesos de la economía nacional en comprar y repartir tierras a campesinos llamados a quebrar por no estar en capacidad de lograr una producción adecuada". ${ }^{207} \mathrm{El}$ sueño de una reforma agraria económicamente sana, moralmente justa, socialmente democrática y prácticamente moderna empezaba a derrumbarse.

En definitiva, el apoyo de Acción Cultural Popular al proyecto de reforma agraria de 1961 no logró acabar con las grandes desigualdades existentes en el país, a pesar de que ACPO le apostó a iniciativas que combinaran los aspectos técnicos y las relaciones sociales del hombre dentro de su contexto en la búsqueda de mejorar la calidad de vida y la productividad del campesinado.

Para acabar con la injusticia social, con las desigualdades, y propiciar el desarrollo, para Salcedo era necesario la creación de riqueza en los diferentes ámbitos del ser humano, abordados a partir de las nociones dadas en las clases radiales. Por eso, en uno de sus últimos textos resumió su punto de vista con la frase "Sin producir riqueza, no se acaba con la pobreza". ${ }^{208}$

\footnotetext{
206. El Campesino, Bogotá, 1 de septiembre de 1963.

207. SALCEDO, José. Diálogos con los líderes, documento preparado por el profesor Lázaro Jiménez Acosta, Bogotá, Editorial Andes, abril de 1974, p. 60

208. SALCEDO, José. Sin producir riqueza no se acaba con la pobreza, Publicaciones Violeta, 1994.
} 


\section{Crisis y cierre de ACPO}

La crisis que llevó a ACPO a su desaparición estuvo relacionada con el apoyo que le había dado la Iglesia Católica y críticas de algunos sectores al trabajo realizado por los campesinos para desarrollar las labores de ACPO, con la financiación y sostenimiento de una institución que cubría buena parte del país y con los cuestionamientos recibidos de algunos empresarios colombianos que veían en ella una posible competencia comercial.

La Iglesia Católica que apoyó inicialmente el trabajo desarrollado por el padre José Joaquín Salcedo y avaló la labor de ACPO, trató de tomar el control de la institución durante la década de los años 60 y 70 al considerar que la razón de la misma debía estar enfocada exclusivamente a la evangelización. Salcedo se opuso considerando que si bien era una obra de la Iglesia Católica debía responder también a las necesidades materiales del campesino. "Los jerarcas vieron en ella un elemento muy eficiente de evangelización y quisieron utilizarla y valorarla solo para este fin pastoral; muy claramente quisieron además que ACPO a través de Radio Sutatenza fuera la voz oficial de la Iglesia en Colombia..." 209

Para que las emisoras de Sutatenza funcionaran como la voz de la Iglesia, se necesitaba que ellas dependieran de manera oficial de la Conferencia Episcopal. La jerarquía católica consideró que como ACPO se había definido como una obra de la Iglesia, a partir de allí podía tener un control total de la organización. Hernando Bernal Alarcón muestra de qué manera la Conferencia Episcopal intentó tomar el control:

“La Conferencia Episcopal no dudó en aprobar una reforma de estatutos de la institución que se hizo en el seno de la misma conferencia, contraviniendo las normas estatutarias de ACPO, mediante resolución B778 de la XXXIV Asamblea (Carta remisoria: 8 de octubre de 1978). En la orientación de esos nuevos estatutos, ACPO pasaría a depender en su actividad educativa y programática de las comisiones pertinentes de la Conferencia Episcopal."210

209. BERNAL, Hernando. "Radio educativa para el desarrollo rural: El precursor Radio Sutatenza y Acción Cultural Popular, su influencia en la región", en Radio y Democracia en América Latina. IPAL - Instituto para América Latina, 1989, p. 94

210. BERNAL, Hernando. Acción Cultural Popular, de la realidad a la utopía, Bogotá, Fundación Cultural Javeriana, 2005, p. 86 
Esta decisión fue apelada por ACPO en los tribunales, quienes le restituyeron su autonomía, mediante sentencia del Consejo de Estado dada el 6 de octubre de 1977. Sin embargo, la posición de los directivos de la organización ocasionó una fractura en el apoyo que había mantenido la jerarquía católica. Es así como la Iglesia Católica colombiana decidió pedirle a la Iglesia Católica alemana que retirara el apoyo y el financiamiento que le hacía a ACPO. Esta decisión empezó a limitar las operaciones de ACPO. Se disminuyó así la formación y capacitación de dirigentes y se afectó "el trabajo de promoción y administración de las escuelas radiofónicas, que era realizado en las comunidades rurales por los dirigentes, líderes y supervisores de origen campesino". ${ }^{211}$

Asegura Bernal Alarcón que ante la decisión de la Iglesia Católica de quitar el apoyo a ACPO, el Gobierno nacional, a la cabeza de Alfonso López Michelsen, decidió reducir y terminar los contratos de servicios que venía prestando la institución en lo relacionado con la educación en las escuelas radiofónicas. En este mismo sentido, Luis Zalamea afirma que el ministro de Educación del momento, Hernando Durán Dussán, recibió a miembros de la Iglesia y funcionarios del Estado, quienes le recomendaron tomar la decisión de suspender los vínculos contractuales con ACPO. ${ }^{212}$

La decisión de la Iglesia Católica colombiana de retirar el apoyo se sumó a las críticas que tenía de varios sectores sobre la labor propiamente educativa que venía desarrollando ACPO. Durante la década de los años 60 se realizaron varios estudios sobre el papel desempeñado por ACPO en el mundo rural y campesino. Uno de ellos fue Los medios de comunicación al servicio del desarrollo rural, dirigido por Stefan Musto, quien hizo un balance del trabajo que llevaba a cabo ACPO, y aunque destacó la importancia de la educación campesina por medio de las escuelas radiofónicas, concluyó que ese trabajo no provocaría ninguna revolución, sino que más bien llevaría a que se dieran frustraciones, pues solo corroboraba la pasividad del campesinado. “ACPO no produce actitudes políticas radicales, sino que cumple una función más bien conciliadora. La población rural, por su parte, no ve en ACPO ninguna fuerza revolucionaria, ni espera de ella cambios radicales". ${ }^{213}$

211. BERNAL, Hernando. Acción Cultural Popular, de la realidad a la utopía, Bogotá, Fundación Cultural Javeriana, 2005, p. 88

212. ZALAMEA, Luis. Un Quijote Visionario. Bogotá, Jorge Plazas S. Editor. 1994, p.241

213. MUSTO, Stefan. Los medios de comunicación al servicio del desarrollo rural, Bogotá, Editorial Andes, 1971, p. 150 
En la misma dirección se manifestaron Camilo Torres y Bertha Corredor, quienes hicieron un estudio denominado Las Escuelas Radiofónicas de Sutatenza. Allí expresaban el convencimiento de que la formación educacionalista de ACPO no estaba orientada a "reformar elementos de estructura", 214 una condición necesaria para conseguir cambios sociales. Es decir, había que llevar a cabo una educación "liberadora" como la llamaría posteriormente Paulo Freire. La crítica en estos estudios, entre otros, llevó a que ACPO quedara en la memoria de un sector del país como una institución de carácter conservador y retardatario.

Alarcón considera que el hecho de no tomar una posición contestataria, como lo pedían algunos sectores cercanos a la Teología de la liberación, llevó a que se diera una distancia entre lo que fue la institución con personería jurídica y el movimiento de base conformado por el campesinado. A la postre lo que sucedió fue el desmonte gradual de la organización local de las escuelas radiofónicas, organización que fue fundamental en los inicios del proyecto de Radio Sutatenza. El desmonte se dio por el temor de que esas organizaciones locales pasaran de ser un grupo radiofónico con reconocimiento, a grupos con fines políticos.

Aparte de los enfrentamientos con la misma Iglesia y con académicos, ACPO también tuvo oposición de un sector de los industriales en el país, quienes veían un riesgo en esta institución por su amplio cubrimiento nacional. Las grandes cadenas radiales "vieron en el incremento de la potencia de las emisoras una seria amenaza para la publicidad de sus emisoras". ${ }^{215}$ Así mismo, la exención de impuestos que tenía la institución por ser de la Iglesia y por realizar una obra social, llevó a que sectores como el de los impresores manifestaran su inconformismo, puesto que la posibilidad de competir así les era desfavorable. Tanto las emisoras como parte del sector editorial "consideraban que la cadena Sutatenza era competencia desleal, porque recibía ayuda del exterior, tenía contratos con el gobierno y además no pagaba impuestos. Y lo mismo se decía de la Editorial Andes y del periódico El Campesino". ${ }^{216}$

Debido a las fuertes confrontaciones con la Iglesia Católica, con determinados sectores industriales y con la crítica a la labor desarrollada en el campo de la educación, ACPO redujo significativamente sus ingresos y debió buscar recursos en

214. TORRES, Camilo y CORREDOR, Bertha. Las escuelas radiofónicas de Sutatenza, Bogotá, Centro de Investigaciones Sociales, 1961, p.54

215. BERNAL, Hernando. "Radio educativa para el desarrollo rural: El precursor Radio Sutatenza y Acción Cultural Popular, su influencia en la región", en Radio y Democracia en América Latina. IPAL - Instituto para América Latina, 1989, p. 118

216. ZALAMEA, Luis. Un Quijote Visionario. Bogotá, Jorge Plazas S. Editor. 1994, p.214 
procesos comerciales que lo llevaron a comprometer su patrimonio, a tal punto que se vio en la necesidad de empezar a vender progresivamente su maquinaria, sus instalaciones y a disminuir el personal, liquidando funcionarios y colaboradores. El Campesino, el 27 de noviembre, mostraba claramente la situación de ACPO, en un artículo titulado La realidad de la situación actual de Acción Cultural Popular: “ACPO ha llegado a una situación financiera muy delicada por las circunstancias del país, la suspensión de ayudas, el endeudamiento y la demora de soluciones reales". 217

A pesar de los continuos llamados para apoyar los servicios de ACPO a través del periódico El Campesino, las deudas adquiridas hicieron inviable el proyecto de ACPO y mostraron la incapacidad de adaptarse a los nuevos retos, llevándola al cierre definitivo ${ }^{218}$. Aunque la personería jurídica de ACPO aún existe, de su objetivo inicial de educar al campesino no queda nada. El periódico EL Campesino fue el último de los medios que utilizó ACPO para la educación. En su edición final prometió volver con un nuevo formato.

217. El Campesino, 27 de noviembre de 1988.

218. Durante el año de 1988, el periódico El Campesino publicó artículos donde mostraba las distintas tareas que realizaba ACPO y pedía apoyo para que continuaran, sin embargo, las ayudas en ese sentido no llegaron y cada uno de los beneficios recibidos por los campesinos fueron desapareciendo. 